\title{
A new atmospheric aerosol phase equilibrium model (UHAERO): organic systems
}

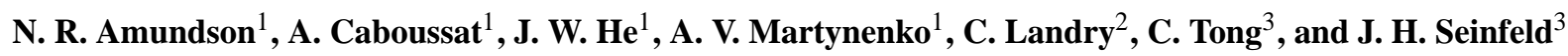 \\ ${ }^{1}$ Department of Mathematics, University of Houston, Houston, USA \\ ${ }^{2}$ Chaire d'Analyse et Simulation Numériques, Ecole Polytechnique Fédérale de Lausanne, Lausanne, Switzerland \\ ${ }^{3}$ Departments of Chemical Engineering and Environmental Science and Engineering, California Institute of Technology, \\ Pasadena, USA
}

Received: 23 May 2007 - Published in Atmos. Chem. Phys. Discuss.: 11 June 2007

Revised: 30 August 2007 - Accepted: 10 September 2007 - Published: 14 September 2007

\begin{abstract}
In atmospheric aerosols, water and volatile inorganic and organic species are distributed between the gas and aerosol phases in accordance with thermodynamic equilibrium. Within an atmospheric particle, liquid and solid phases can exist at equilibrium. Models exist for computation of phase equilibria for inorganic/water mixtures typical of atmospheric aerosols; when organic species are present, the phase equilibrium problem is complicated by organic/water interactions as well as the potentially large number of organic species. We present here an extension of the UHAERO inorganic thermodynamic model (Amundson et al., 2006c) to organic/water systems. Phase diagrams for a number of model organic/water systems characteristic of both primary and secondary organic aerosols are computed. Also calculated are inorganic/organic/water phase diagrams that show the effect of organics on inorganic deliquescence behavior. The effect of the choice of activity coefficient model for organics on the computed phase equilibria is explored.
\end{abstract}

\section{Introduction}

Atmospheric particles are generally a mixture of inorganic and organic components and water. Water and other volatile species are distributed between the gas and aerosol phases in accordance with thermodynamic equilibrium, and the quantities of these species in the aerosol phase at given conditions of temperature and relative humidity are determined by the conditions of that equilibrium. A great deal of work has been carried out on the development of thermodynamic models of atmospheric aerosols, as such models are an essential component of more comprehensive atmospheric chemical transport models that treat aerosols. A recent summary of a number of existing thermodynamic models for inor-

Correspondence to: J. H. Seinfeld

(seinfeld@caltech.edu) ganic aerosols is given by Amundson et al. (2006c). Thermodynamic models of aerosols containing organic material have also received considerable attention (Saxena and Hildemann, 1997; Ansari and Pandis, 2000; Clegg et al., 2001, 2003; Pankow et al., 2001; Seinfeld et al., 2001; Ming and Russell, 2002; Topping et al., 2005; Clegg and Seinfeld, 2006a,b; Metzger et al., 2006; Amundson et al., 2007). Aerosol thermodynamic models that are imbedded within atmospheric chemical transport models predict, at any time, the gas-particle distribution of volatile species. In the case of inorganic particles, the equilibrium calculation determines whether the aerosol phase is liquid, solid, or a mixture of solid and aqueous phases. When organics are present as well, current models that include both inorganics and organics assume a priori either that particles consist of a single-phase inorganic-organic-water mixture or that each particle consists of an aqueous phase that contains largely inorganics and water and an organic phase (e.g. Griffin et al., 2002, 2003, 2005). Whereas predicting the phase state of the mixture is a cornerstone of inorganic aerosol models, organic aerosol models do not yet generally have this capability. Predicting the phase state of atmospheric organic-containing particles is important for a variety of reasons. For example, the presence of organic species in solution may substantially influence the phase transitions that occur when salts deliquesce and effloresce; likewise, dissolved electrolytes can have appreciable effects on the solubility of organic components in solution. A new inorganic atmospheric aerosol phase equilibrium model, termed UHAERO, was introduced by Amundson et al. (2006c). In the present work UHAERO is extended for determining the phase equilibrium of organicwater systems. The next section is devoted to a brief summary of the mathematical approach to solving the equilibrium problem, the details of which are given elsewhere (Amundson et al., 2005b, 2006b). Section 3 discusses general characteristics of organic phase equilibria, and presents a number of examples of organic phase equilibria calculated

Published by Copernicus Publications on behalf of the European Geosciences Union. 
with the model. In Sect. 4 we calculate the effect of organic phase equilibria on inorganic deliquescence behavior. Finally, in Sect. 5 we evaluate the sensitivity of the predicted phase diagram in one system (1-hexacosanol/pinic $\mathrm{acid} / \mathrm{water}$ ) to the activity coefficient model used.

\section{Modeling approach}

The liquid phase equilibrium problem (PEP) for a system of $n_{s}$ substances in $\pi$ phases at a specified temperature $T$ and pressure $P$ and for a given total substance abundance in units of moles is the solution of the constrained minimization problem:

$$
\min G\left(y_{1}, \ldots, y_{\pi} ; \boldsymbol{x}_{1}, \ldots, \boldsymbol{x}_{\pi}\right)=\sum_{\alpha=1}^{\pi} y_{\alpha} g\left(\boldsymbol{x}_{\alpha}\right)
$$

subject to

$$
\begin{array}{r}
\boldsymbol{x}_{\alpha}>0, \quad y_{\alpha} \geq 0, \quad \alpha=1,2, \ldots, \pi, \\
\sum_{\alpha=1}^{\pi} y_{\alpha} \boldsymbol{x}_{\alpha}=\boldsymbol{b},
\end{array}
$$

where $y_{\alpha}$ is the total number of moles in phase $\alpha, \mathbf{x}_{\alpha}$ is the mole fraction vector (of dimension $n_{S}$ ) for phase $\alpha, g\left(\boldsymbol{x}_{\alpha}\right)$ is the molar Gibbs free energy for phase $\alpha$, and $\mathbf{b}$ is the $n_{s^{-}}$ dimensional vector of the total substance abundances. Condition (2) expresses the fact that in calculating the partition of species $j$, for $j=1, \ldots, n_{s}$, among $\pi$ phases, the total quantity of species $j$ is conserved and equals the feed $b_{j}$. Relation (1) characterizes the phase equilibrium as the global minimum of the total Gibbs free energy, $G$, of the system.

The molar Gibbs free energy (GFE) $g$ is the relevant thermodynamic function for the PEP, and is usually defined for the mole fraction vector $\boldsymbol{x}$ by $g(\boldsymbol{x})=\boldsymbol{x}^{T} \boldsymbol{\mu}(\boldsymbol{x})$, with $\boldsymbol{x}^{T} \boldsymbol{\mu}(\boldsymbol{x})$ denoting the scalar product of the two vectors $\boldsymbol{x}$ and $\boldsymbol{\mu}(\boldsymbol{x})$. The chemical potential vector $\boldsymbol{\mu}(\boldsymbol{x})$ is given by

$\boldsymbol{\mu}(\boldsymbol{x})=\boldsymbol{\mu}^{0}+R T \ln \boldsymbol{a}(\boldsymbol{x})$,

where $R$ is the universal gas constant, $\boldsymbol{\mu}^{0}$ is the standard chemical potential vector of liquid species, and $\boldsymbol{a}(\boldsymbol{x})$ is the activity vector at the mole fraction vector $\boldsymbol{x}$. On a mole fraction scale, the activity of component $j$, for $j=1, \ldots, n_{s}$, is expressed as $a_{j}=f_{j} x_{j}$, where $f_{j}$ is the mole fraction-based activity coefficient, and $x_{j}$ is the mole fraction of species $j$. The PEP as stated in (1) can be reformulated in a normalized form:

$\min G_{n}\left(y_{1}, \ldots, y_{\pi} ; \boldsymbol{x}_{1}, \ldots, \boldsymbol{x}_{\pi}\right)=\sum_{\alpha=1}^{\pi} y_{\alpha} g_{n}\left(\boldsymbol{x}_{\alpha}\right)$

subject to condition (2). In (3), the normalized molar GFE $g_{n}$ is defined for the mole fraction vector $\boldsymbol{x}$ by $g_{n}(\boldsymbol{x})=\boldsymbol{x}^{T} \ln \boldsymbol{a}(\boldsymbol{x})$ and is related to the molar GFE $g$ by $g_{n}(\boldsymbol{x})=\left(g(\boldsymbol{x})-\boldsymbol{x}^{T} \boldsymbol{\mu}^{0}\right) / R T$. We also have the relation
$G_{n}=\left(G-b^{T} \boldsymbol{\mu}^{0}\right) / R T$ for the normalized total GFE of the system. The fact that the normalization relates $G$ to $G_{n}$, via first a shift by the constant $\boldsymbol{b}^{T} \boldsymbol{\mu}^{0}$ then a scaling by the constant $R T$, implies that the two formulations (1) and (3) of the PEP are equivalent; that is, if $\left\{y_{\alpha}, \boldsymbol{x}_{\alpha}\right\}_{\alpha=1, \pi}$ is the solution of (1) for the feed vector $\boldsymbol{b}$, it is also the solution of (3) for the same feed vector $\boldsymbol{b}$, and the converse is also true. In the formulation of the PEP, we assume that all the phases in the system belong to the same phase class so that the molar GFE, $g$ or $g_{n}$, is the same for all phases; we assume also that all substances can partition into all phases and that no reactions occur between the different substances. We are interested in determining the state of the system at the thermodynamic equilibrium, i.e. the number of phases $\pi$ and their compositions $\left\{y_{\alpha}, \boldsymbol{x}_{\alpha}\right\}_{\alpha=1, \pi}$.

The detailed description of the numerical solution of the PEP by a primal-dual interior-point algorithm is given by Amundson et al. (2005b, 2006b). Essentially, the numerical minimization technique relies on a geometrical concept of phase simplex of the convex hull of the normalized GFE $g_{n}$ to characterize an equilibrium solution that corresponds to a global minimum of the total GFE $G_{n}$. The algorithm is started from an initial solution involving all possible phases in the system, and applies, at each iteration step, a Newton method to the Karush-Kuhn-Tucker optimality system of (3), perturbed by a log-barrier penalty term, to find the next primal-dual approximation of the solution of (3). A secondorder phase stability criterion is incorporated to ensure that the algorithm converges (quadratically) to a stable equilibrium rather than to any other first-order optimality point such as a maximum, a saddle point, or an unstable local minimum.

The key parameters in the phase equilibrium calculation are the mole fraction-based activity coefficients $f_{j}$, $j=1, \ldots, n_{s}$, as functions of the mole fraction vector $\boldsymbol{x}$. Atmospheric aerosols comprise a wide range of organic species of diverse chemical structures. The approach that has generally been adopted in thermodynamic modeling of organic aerosol mixtures is to represent the mixture in terms of the organic functional groups present. UNIFAC (UNIQUAC Functional Group Activity Coefficients), a semi-empirical thermodynamic model applying the group contribution concept in which the mixture consists not of molecules but of functional groups, is a well-established method for estimating activity coefficients $f_{j}$ of organic mixtures (Fredenslund et al., 1977; Sandler, 1999). The availability of an extensive set of UNIFAC group-interaction parameters permits the characterization of complex mixtures of virtually all organic compounds of atmospheric interest (Gmehling, 1999; Wittig et al., 2003).

What is ultimately needed in a 3-D atmospheric model is a thermodynamic model that computes both the gas-aerosol partitioning and the aerosol phase equilibrium, whose mathematical formulation is given as

$\min G\left(\boldsymbol{n}_{l}, \boldsymbol{n}_{g}, \boldsymbol{n}_{s} ; y_{1}, \ldots, y_{\pi} ; \boldsymbol{x}_{1}, \ldots, \boldsymbol{x}_{\pi}\right)$ 
$=\boldsymbol{n}_{g}^{T} \boldsymbol{\mu}_{g}+\boldsymbol{n}_{s}^{T} \boldsymbol{\mu}_{s}+\sum_{\alpha=1}^{\pi} y_{\alpha} g\left(\boldsymbol{x}_{\alpha}\right)$,

subject to

$$
\begin{aligned}
& \boldsymbol{n}_{g}>\mathbf{0}, \quad \boldsymbol{n}_{l}>\mathbf{0}, \quad \boldsymbol{n}_{s} \geq \mathbf{0} \\
& \boldsymbol{x}_{\alpha}>0, \quad y_{\alpha} \geq 0, \quad \alpha=1,2, \ldots, \pi \\
& \boldsymbol{A}_{g} \boldsymbol{n}_{g}+\boldsymbol{A}_{l} \boldsymbol{n}_{l}+\boldsymbol{A}_{s} \boldsymbol{n}_{s}=\boldsymbol{b} \\
& \sum_{\alpha=1}^{\pi} y_{\alpha} \boldsymbol{x}_{\alpha}=\boldsymbol{n}_{l},
\end{aligned}
$$

where $\boldsymbol{n}_{g}, \boldsymbol{n}_{l}, \boldsymbol{n}_{s}$ are the concentration vectors in gas, liquid, and solid phases, respectively, $\boldsymbol{\mu}_{g}$ and $\boldsymbol{\mu}_{s}$ are the corresponding chemical potential vectors for gas and solid species, $\boldsymbol{A}_{g}$, $\boldsymbol{A}_{l}, \boldsymbol{A}_{s}$ are the component-based formula matrices, and $\boldsymbol{b}$ is the component-based feed vector. Condition (5) expresses the fact, for example, that in calculating the partition of any chemical component (electrolytes and/or organic species) among gas, liquid and solid phases the total concentration is conserved, while maintaining a charge balance in solution. Condition (6) is similar to condition (2) stating that in calculating the partition of liquid species $j$, for $j=1, \ldots, n_{s}$, among $\pi$ phases, the total quantity of species $j$ is conserved and equals the total abundance $n_{l, j}$ of liquid species $j$. The chemical potential vectors for gas and solid species are given by

$\boldsymbol{\mu}_{g}=\boldsymbol{\mu}_{g}^{0}+R T \ln \boldsymbol{a}_{g}$,

$\mu_{s}=\mu_{s}^{0}$,

where $\boldsymbol{\mu}_{g}^{0}$ and $\boldsymbol{\mu}_{s}^{0}$ are the standard chemical potentials of gas and solid species, respectively, and $\boldsymbol{a}_{g}$ is the activity vector of the gas species.

Again, the key issue in the phase and chemical equilibrium calculation of (4) is the estimation of the activity coefficients $f_{i}$ as a function of the mole fraction vector $\boldsymbol{x}$ for a liquid phase. If both electrolytes and organic species are present, the general thermodynamic model used in the present application is based on a hybrid approach, namely, the so-called CSB model (Clegg et al., 2001; Clegg and Seinfeld, 2006a,b), where the activity coefficients for the electrolytes and the non-electrolyte organics are computed independently, with the Pitzer, Simonson, Clegg (PSC) mole fraction-based model (Clegg and Pitzer, 1992; Clegg et al., 1992) for water/electrolytes mixtures and UNIFAC models for water/non-electrolyte organic mixtures, respectively.

The CSB model is necessarily based upon the assumption of a single solvent (water) in which ions and organic molecules are dissolved. Additional terms for electrolyte/non-electrolyte organic contributions to the activity coefficients are consequently expressed on a molality basis from the model of Pitzer. The CSB modeling approach is not intended to be applied to mixed solvent systems containing both electrolytes and organic species such as those considered in Sect. 4. Such liquids may have an organic phase present at equilibrium that contains very little water, and the Pitzer model for electrolyte/non-electrolyte organic contributions to the activity coefficients would be unlikely to be accurate over the full range of compositions and concentrations. There are many other uncertainties affecting the interactions between electrolytes and non-electrolyte organics, largely caused by a lack of data, which affect both liquid/liquid and liquid/solid equilibrium (Clegg et al., 2001). Consequently the terms in the Pitzer model for interactions between electrolytes and non-electrolyte organics are not included in the thermodynamic equilibrium calculations presented in this paper. Raatikainen and Laaksonen (2005) reviewed a number of other water/organic/electrolyte activity coefficient models and identified a lack of experimental thermodynamic data as a major constraint to the development of accurate models. The effect of interactions between electrolytes and non-electrolyte organics on the liquid phase equilibria and on the inorganic deliquescence properties of inorganic/organic/water mixtures will be a subject of future studies.

In Amundson et al. (2006c), a new inorganic atmospheric aerosol phase equilibrium model, termed UHAERO, was introduced that is based on a computationally efficient minimization of the GFE, $G$, defined as in (4), but for pure inorganic gas-aerosol equilibrium, which is a computationally simpler problem where the number of liquid phases is limited to one, i.e. $\pi=1$, and the activity coefficients of aqueous inorganic electrolyte solutions are predicted by the PSC model. The special algebraic structure of the pure inorganic gas-aerosol equilibrium problem was taken advantage of in the numerical minimization technique of UHAERO that is based on a primal-dual active-set algorithm Amundson et al. (2005a, 2006a). In Amundson et al. (2007), UHAERO is extended to include water-soluble organic compounds to account for the influence of organic solutes in electrolyte mixtures, with application to dicarboxylic acids: oxalic, malonic, succinic, glutaric, maleic, malic, and methyl succinic acids. Activity coefficients in inorganic/organic/water mixtures are predicted via the hybrid CSB model that combines the PSC model for inorganic multicomponent solutions and the UNIFAC model for water/organic mixtures. We note that, compared to pure inorganic gas-aerosol equilibrium, the addition of water soluble organic compounds neither changes the number of liquid phases in equilibrium, i.e. $\pi$ remains as 1 and the aqueous phase is the only liquid phase at equilibrium, nor alters the special algebraic structure characterizing the underlying phase equilibrium. Therefore, the same numerical minimization technique of UHAERO, namely, the primal-dual active-set algorithm as presented in Amundson et al. (2005a, 2006a), is employed again in Amundson et al. (2007) for mixed inorganic/(water soluble) organic gas-aerosol equilibrium calculations. As an example, with the inclusion of one dicarboxylic acid, denoted by $\mathrm{H}_{2} \mathrm{R}$, to the sulfate/ammonium/water system, the additional organic species, namely, $\mathrm{H}_{2} \mathrm{R}$ (gas), $\mathrm{H}_{2} \mathrm{R}$ (aqueous), $\mathrm{HR}^{-}$ 
Table 1. Organic compounds considered and their UNIFAC groups.

\begin{tabular}{lllll}
\hline $\begin{array}{l}\text { Species } \\
\#\end{array}$ & $\begin{array}{l}\text { Compound } \\
\text { name }\end{array}$ & $\begin{array}{l}\text { Carbon } \\
\text { number }\end{array}$ & Structure & UNIFAC \\
\hline $\mathrm{X} 1$ & 2-hydroxy-glutaric acid & $(\mathrm{C} 5)$ & chain & $2 \mathbb{C H}_{2}, 1 \mathbb{C H}, 1 \mathrm{OH}, 2 \mathbb{C O O H}$ \\
$\mathrm{X} 2$ & adipic acid & $(\mathrm{C} 6)$ & chain & $4 \mathbb{C H}_{2}, 2 \mathbb{C O O H}$ \\
$\mathrm{X} 3$ & glutaraldehyde & $(\mathrm{C} 5)$ & chain & $3 \mathbb{C H}_{2}, 2 \mathbb{C H O}$ \\
$\mathrm{X} 4$ & palmitic acid & $(\mathrm{C} 16)$ & chain & $1 \mathbb{C H}_{3}, 14 \mathbb{C H}_{2}, 1 \mathbb{C O O H}$ \\
$\mathrm{X} 5$ & 1-hexacosanol & $(\mathrm{C} 26)$ & chain & $1 \mathbb{C H}_{3}, 25 \mathbb{C H}_{2}, 1 \mathrm{OH}$ \\
$\mathrm{X} 6$ & nonacosane & $(\mathrm{C} 29)$ & chain & $2 \mathbb{C H}_{3}, 27 \mathbb{C H}_{2}$ \\
$\mathrm{X} 7$ & pinic acid & $(\mathrm{C} 9)$ & complex & $2 \mathbb{C H}_{3}, 2 \mathbb{C H}_{2}, 2 \mathbb{C H}, 1 \mathbb{C}, 2 \mathbb{C O O H}$ \\
$\mathrm{X} 8$ & pinonic acid & $(\mathrm{C} 10)$ & complex & $2 \mathbb{C H}_{3}, 2 \mathbb{C H}_{2}, 2 \mathbb{C H}, 1 \mathbb{C}, 1 \mathbb{C} \mathrm{CH}_{3} \mathbb{C O}, 1 \mathbb{C O O H}$ \\
\hline
\end{tabular}

Table 2. UNIFAC energy interaction parameters between the main groups used in this work: UNIFAC/UNIFAC-Peng/UNIFAC-LL.

\begin{tabular}{ccccccc}
\hline & $\mathrm{CH}_{2}$ & $\mathrm{OH}$ & $\mathrm{H}_{2} \mathrm{O}$ & $\mathbb{C O}$ & $\mathbb{C H O}$ & $\mathbb{C O O H}$ \\
\hline $\mathrm{CH}_{2}$ & $\times$ & $986.5 / 986.5 / 644.6$ & $1318 . / 1318 . / 1300$. & $476.4 / 476.4 / 472.6$ & $677.0 / 677.0 / 158.1$ & $663.5 / 663.5 / 139.4$ \\
$\mathrm{OH}$ & $156.4 / 156.4 / 328.2$ & $\times$ & $353.5 / 265.97 / 28.73$ & same & same & $199.0 / 224.4 /-104.0$ \\
$\mathrm{H}_{2} \mathrm{O}$ & $300.0 / 300.0 / 342.4$ & $-229.1 /-467.4 /-122.4$ & $\times$ & $-195.4 /-195.4 /-171.8$ & $-116.0 /-116.0 /-349.9$ & $-14.09 /-69.29 /-465.7$ \\
$\mathbb{C O}$ & $26.76 / 26.76 / 66.56$ & same & $472.5 / 472.5 / 634.8$ & $\times$ & same & $669.4 / 669.4 / 1247$. \\
$\mathbb{C H O}$ & $505.7 / 505.7 / 146.1$ & same & $480.8 / 480.8 / 623.7$ & same & $\times$ & $497.5 / 497.5 / 0.750$ \\
$\mathbb{C O O H}$ & $315.3 / 315.3 / 1744$. & $-151.0 /-103.0 / 118.4$ & $-66.17 /-145.9 / 652.3$ & $-297.8 /-297.8 /-101.3$ & $-165.5 /-165.5 / 1051$. & $\times$ \\
\hline
\end{tabular}

(aqueous), $\mathrm{R}^{2-}$ (aqueous), $\mathrm{H}_{2} \mathrm{R}$ (solid), $\left(\mathrm{NH}_{4}\right)_{2} \mathrm{R}$ (solid), are treated computationally in the same way as inorganic species. In the present work, UHAERO is further extended to include organic compounds that may not be water soluble. Therefore, in equilibrium, multiple liquid phases are allowed to form, i.e. $\pi>1$, and their equilibrium compositions $\left\{y_{\alpha}, \boldsymbol{x}_{\alpha}\right\}_{\alpha=1, \pi}$ are to be determined. Again, the CSB hybrid approach is employed for the activity coefficient calculation of inorganic/organic/water mixtures. In addition, the underlying numerical minimization technique of UHAERO in the present work is a hybrid one that combines the primal-dual active-set algorithm for the gas-aerosol (i.e. electrolyte solution and solids) equilibrium with the primal-dual interiorpoint algorithm for the liquid phase equilibrium. Therefore, the overall computational efficiency of the hybrid solution method is dictated by the efficiency of two underlying numerical minimization techniques.

\section{Characteristics of organic phase equilibria}

The method for determining organic/water phase equilibria developed here treats, in general, any number of organic compounds. The organic fraction of atmospheric aerosols comprises a complex mixture of compounds from direct emissions and atmospheric gas-to-particle conversion. Even if all compounds were known, inclusion of all in an atmospheric model is infeasible. Consequently, one approach is to represent the complex mixture by a set of model compounds that span the range of properties characteristic of the actual ambient mixture (see, for example, Pun et al., 2002). The set of surrogate compounds should include ones that display characteristics of primary and secondary organics. Primary organics tend to be longer chain aliphatic (and aromatic) species, whereas oxidized secondary species are characterized by the presence of $-\mathrm{OH},-\mathrm{COOH}$, and $-\mathrm{CHO}$ groups. Those chosen for detailed study here are given in Table 1. Palmitic acid (X4), 1-hexacosonol (X5), and nonacosane (X6) are characteristic of primary organic aerosol material, whereas 2-hydroxy-glutaric acid (X1), adipic acid (X2), glutaraldehyde (X3), pinic acid (X7), and pinonic acid (X8) represent secondary species. Adipic acid and pinic acid/pinonic acid are products of the atmospheric oxidation of cyclohexene and alpha-pinene, respectively.

Table 2 shows the three different sets of UNIFAC parameters used in this study. Sets of UNIFAC interaction parameters were derived from vapor-liquid (Hansen et al., 1991) and liquid-liquid equilibrium data (Magnussen et al., 1981). The most widely used set of parameters derived from vapor-liquid data is referred to as UNIFAC, while those from liquid-liquid equilibrium data are denoted by UNIFAC-LL. UNIFACPeng parameters are mostly consistent with UNIFAC parameters, except Peng et al. (2001) modified the functional group interaction parameters of the $\mathrm{COOH} / \mathrm{H}_{2} \mathrm{O}, \mathrm{OH} / \mathrm{H}_{2} \mathrm{O}$, and $\mathrm{OH} / \mathrm{COOH}$ pairs by fitting the UNIFAC model to measured data. 
Table 3. Two-phase equilibrium solutions for binary systems.

\begin{tabular}{|c|c|c|c|c|c|c|}
\hline \multirow[b]{2}{*}{$\begin{array}{l}\text { system } \\
\left(s_{1} / s_{2}\right)\end{array}$} & \multicolumn{2}{|c|}{ UNIFAC } & \multicolumn{2}{|c|}{ UNIFAC-Peng } & \multicolumn{2}{|c|}{ UNIFAC-LL } \\
\hline & $\begin{array}{l}{\left[x_{s_{2}}^{(1)},\right.} \\
\left.x_{s_{2}}^{(2)}\right]\end{array}$ & $\begin{array}{l}\left(a_{s_{1}}^{(12)},\right. \\
\left.a_{s_{2}}^{(12)}\right)\end{array}$ & $\begin{array}{l}{\left[x_{s_{2}}^{(1)},\right.} \\
\left.x_{s_{2}}^{(2)}\right]\end{array}$ & $\begin{array}{l}\left(a_{s_{1}}^{(12)},\right. \\
\left.a_{s_{2}}^{(12)}\right)\end{array}$ & $\begin{array}{l}{\left[x_{s_{2}}^{(1)},\right.} \\
\left.x_{s_{2}}^{(2)}\right]\end{array}$ & $\begin{array}{l}\left(a_{s_{1}}^{(12)},\right. \\
\left.a_{s_{2}}^{(12)}\right)\end{array}$ \\
\hline water/X1 & none & none & none & none & none & none \\
\hline water/X2 & none & none & none & none & none & none \\
\hline water/X3 & $\begin{array}{l}{[9.365 \mathrm{e}-02} \\
3.453 \mathrm{e}-01]\end{array}$ & $\begin{array}{l}(9.603 \mathrm{e}-01 \\
7.754 \mathrm{e}-01)\end{array}$ & $\begin{array}{l}{[9.365 \mathrm{e}-02} \\
3.453 \mathrm{e}-01]\end{array}$ & $\begin{array}{l}(9.603 \mathrm{e}-01 \\
7.754 \mathrm{e}-01)\end{array}$ & $\begin{array}{l}{[4.895 \mathrm{e}-02,} \\
2.834 \mathrm{e}-01]\end{array}$ & $\begin{array}{l}(9.741 \mathrm{e}-01 \\
5.742 \mathrm{e}-01)\end{array}$ \\
\hline water/X4 & $\begin{array}{l}\text { [1.188e-07, } \\
8.433 \mathrm{e}-01]\end{array}$ & $\begin{array}{l}(1-3.22 \mathrm{e}-07 \\
8.552 \mathrm{e}-01)\end{array}$ & $\begin{array}{l}{[2.129 \mathrm{e}-07} \\
7.585 \mathrm{e}-01]\end{array}$ & $\begin{array}{l}(1-4.06 \mathrm{e}-07 \\
7.671 \mathrm{e}-01)\end{array}$ & $\begin{array}{l}{[2.547 \mathrm{e}-08,} \\
9.830 \mathrm{e}-01]\end{array}$ & $\begin{array}{l}(1-2.88 \mathrm{e}-07 \\
9.848 \mathrm{e}-01)\end{array}$ \\
\hline water/X5 & $\begin{array}{l}{[2.061 \mathrm{e}-12,} \\
8.984 \mathrm{e}-01]\end{array}$ & $\begin{array}{l}(1-2.12 \mathrm{e}-07 \\
9.093 \mathrm{e}-01)\end{array}$ & $\begin{array}{l}{[4.020 \mathrm{e}-12,} \\
7.246 \mathrm{e}-01]\end{array}$ & $\begin{array}{l}(1-1.80 \mathrm{e}-06, \\
5.996 \mathrm{e}-01)\end{array}$ & $\begin{array}{l}{[2.711 \mathrm{e}-13,} \\
9.142 \mathrm{e}-01]\end{array}$ & $\begin{array}{l}(1-2.05 \mathrm{e}-07 \\
9.196 \mathrm{e}-01)\end{array}$ \\
\hline water/X6 & $\begin{array}{l}{[8.633 \mathrm{e}-16,} \\
9.976 \mathrm{e}-01]\end{array}$ & $\begin{array}{l}(1-8.50 \mathrm{e}-08, \\
9.977 \mathrm{e}-01)\end{array}$ & $\begin{array}{l}{[8.633 \mathrm{e}-16,} \\
9.976 \mathrm{e}-01]\end{array}$ & $\begin{array}{l}(1-8.50 \mathrm{e}-08, \\
9.977 \mathrm{e}-01)\end{array}$ & $\begin{array}{l}{[1.000 \mathrm{e}-16,} \\
9.976 \mathrm{e}-01]\end{array}$ & $\begin{array}{l}(1-2.69 \mathrm{e}-07 \\
9.976 \mathrm{e}-01)\end{array}$ \\
\hline water/X7 & $\begin{array}{l}{[3.351 \mathrm{e}-03,} \\
3.655 \mathrm{e}-01]\end{array}$ & $\begin{array}{l}(9.970 \mathrm{e}-01 \\
3.980 \mathrm{e}-01)\end{array}$ & $\begin{array}{l}{[8.575 \mathrm{e}-03,} \\
2.076 \mathrm{e}-01]\end{array}$ & $\begin{array}{l}(9.935 \mathrm{e}-01 \\
1.910 \mathrm{e}-01)\end{array}$ & $\begin{array}{l}{[4.147 \mathrm{e}-03,} \\
3.508 \mathrm{e}-01]\end{array}$ & $\begin{array}{l}(9.964 \mathrm{e}-01 \\
4.407 \mathrm{e}-01)\end{array}$ \\
\hline water/X8 & $\begin{array}{l}{[1.049 \mathrm{e}-03,} \\
4.922 \mathrm{e}-01]\end{array}$ & $\begin{array}{l}(9.990 \mathrm{e}-01, \\
5.329 \mathrm{e}-01)\end{array}$ & $\begin{array}{l}{[1.561 \mathrm{e}-03,} \\
3.894 \mathrm{e}-01]\end{array}$ & $\begin{array}{l}(9.985 \mathrm{e}-01, \\
3.797 \mathrm{e}-01)\end{array}$ & $\begin{array}{l}{[1.078 \mathrm{e}-03,} \\
4.977 \mathrm{e}-01]\end{array}$ & $\begin{array}{l}(9.990 \mathrm{e}-01, \\
6.036 \mathrm{e}-01)\end{array}$ \\
\hline $\mathrm{X} 1 / \mathrm{X} 2$ & none & none & none & none & none & none \\
\hline $\mathrm{X} 1 / \mathrm{X} 3$ & none & none & none & none & $\begin{array}{l}{[5.832 \mathrm{e}-01,} \\
8.398 \mathrm{e}-01]\end{array}$ & $\begin{array}{l}(6.896 \mathrm{e}-01, \\
9.376 \mathrm{e}-01)\end{array}$ \\
\hline $\mathrm{X} 1 / \mathrm{X} 4$ & $\begin{array}{l}{[2.893 \mathrm{e}-03,} \\
9.808 \mathrm{e}-01]\end{array}$ & $\begin{array}{l}(9.972 \mathrm{e}-01, \\
9.821 \mathrm{e}-01)\end{array}$ & $\begin{array}{l}{[2.885 \mathrm{e}-03,} \\
9.809 \mathrm{e}-01]\end{array}$ & $\begin{array}{l}(9.972 \mathrm{e}-01, \\
9.823 \mathrm{e}-01)\end{array}$ & $\begin{array}{l}{[1.546 \mathrm{e}-03,} \\
9.592 \mathrm{e}-01]\end{array}$ & $\begin{array}{l}(9.985 \mathrm{e}-01, \\
9.628 \mathrm{e}-01)\end{array}$ \\
\hline $\mathrm{X} 1 / \mathrm{X} 5$ & $\begin{array}{l}{[2.724 \mathrm{e}-05} \\
9.797 \mathrm{e}-01]\end{array}$ & $\begin{array}{l}(1-2.73 \mathrm{e}-05 \\
9.800 \mathrm{e}-01)\end{array}$ & $\begin{array}{l}{[2.453 \mathrm{e}-05} \\
9.846 \mathrm{e}-01]\end{array}$ & $\begin{array}{l}(1-2.47 \mathrm{e}-05, \\
9.850 \mathrm{e}-01)\end{array}$ & $\begin{array}{l}{[3.744 \mathrm{e}-05} \\
9.198 \mathrm{e}-01]\end{array}$ & $\begin{array}{l}(1-3.75 e-05 \\
9.250 e-01)\end{array}$ \\
\hline $\mathrm{X} 1 / \mathrm{X} 6$ & $\begin{array}{l}{[1.853 \mathrm{e}-07} \\
1-8.29 \mathrm{e}-05]\end{array}$ & $\begin{array}{l}(1-3.52 \mathrm{e}-07 \\
1-9.25 \mathrm{e}-05)\end{array}$ & $\begin{array}{l}{[1.934 \mathrm{e}-07} \\
1-9.96 \mathrm{e}-05]\end{array}$ & $\begin{array}{l}(1-3.61 \mathrm{e}-07 \\
1-9.87 \mathrm{e}-05)\end{array}$ & $\begin{array}{l}\text { [4.582e-07, } \\
9.894 \mathrm{e}-01]\end{array}$ & $\begin{array}{l}(1-6.22 \mathrm{e}-07 \\
9.8960 \mathrm{e}-01)\end{array}$ \\
\hline $\mathrm{X} 1 / \mathrm{X}[7,8]$ & none & none & none & none & none & none \\
\hline $\mathrm{X} 2 / \mathrm{X} 3$ & none & none & none & none & none & none \\
\hline
\end{tabular}

Tables 3 and 4 present the complete set of binary and ternary mixtures, respectively, studied here. For each mixture the characteristics of the phase equilibrium are summarized for each of the three different activity coefficient models, UNIFAC, UNIFAC-Peng, and UNIFAC-LL. In the column of Table 3 corresponding to each of the activity coefficient models, the set $\left\{x_{s_{2}}^{(1)}, x_{s_{2}}^{(2)}\right\}$ represents the mole fractions of component 2 at which the two equilibrium phases are located, $x_{s_{2}}^{(1)}$ and $x_{s_{2}}^{(2)}$, and the corresponding equilibrium activities for each component, $a_{s_{1}}^{(12)}$ and $a_{s_{2}}^{(12)}$. The entry "none" in Table 3 indicates that no two-phase equilibrium is predicted for the system. For binary systems, both UNIFAC and UNIFAC-Peng parameters predict similar results, as the two sets of parameters are largely identical. On the other hand, the UNIFAC-LL parameters predict different phase solutions for $\mathrm{X} 1 / \mathrm{X} 3, \mathrm{X} 2 / \mathrm{X}(4,5)$. X3/X(4-6), X5/X(7,8), and X6/X7. As shown in Table 2, the UNIFAC-LL parameters are significantly different from those of UNIFAC and UNIFAC-Peng, leading to the differences in the predictions. We address this issue subsequently

The three-phase equilibrium solutions are presented in Table 4 for all possible ternary systems among the 8 organics and water. The sets, $\left\{x_{s_{2}}^{(1)}, x_{s_{2}}^{(2)}, x_{s_{2}}^{(3)}\right\}$ and $\left\{x_{s_{3}}^{(1)}, x_{s_{3}}^{(2)}, x_{s_{3}}^{(3)}\right\}$, denote the mole fractions of components 2 and 3, respectively, in the equilibrium phases 1, 2 and 3, with corresponding equilibrium activities for each component, $a_{s_{1}}^{(123)}, a_{s_{2}}^{(123)}$ and $a_{S_{3}}^{(123)}$. An entry "none" indicates that a three-phase equilibrium is not predicted for the system. Unlike the results for binary systems, there is general agreement for the phase behavior (i.e. whether a three-phase equilibrium is present in a system or not) predicted for all three sets of UNIFAC parameters. However, the predicted values of the equilibrium phase locations, $\left\{x_{s_{2}}^{(1)}, x_{s_{2}}^{(2)}, x_{s_{2}}^{(3)}\right\}$ and $\left\{x_{s_{3}}^{(1)}, x_{s_{3}}^{(2)}, x_{s_{3}}^{(3)}\right\}$, and the activities of each component at equilibrium, $a_{s_{1}}^{(123)}, a_{s_{2}}^{(123)}$ and $a_{S_{3}}^{(123)}$, are quite different for UNIFAC-LL, while those from UNIFAC and UNIFAC-Peng are largely consistent with each other.

In the remainder of this section, we focus on the reconstruction of the phase diagram at $298.15 \mathrm{~K}$ by UNIFAC for four ternary systems, namely water/1-hexacosanol(X5)/pinic $\operatorname{acid}(\mathrm{X} 7)$, water/adipic acid(X2)/glutaraldehyde(X3), water/pinonic $\operatorname{acid}(\mathrm{X} 8)$ /nonacosane(X6), and water/2-hydroxy-glutaric $\operatorname{acid}(\mathrm{X} 1) /$ palmitic $\operatorname{acid}(\mathrm{X} 4)$. We begin our analysis of the 
Table 3. Continued.

\begin{tabular}{|c|c|c|c|c|c|c|}
\hline \multirow[b]{2}{*}{$\begin{array}{l}\text { system } \\
\left(s_{1} / s_{2}\right)\end{array}$} & \multicolumn{2}{|c|}{ UNIFAC } & \multicolumn{2}{|c|}{ UNIFAC-Peng } & \multicolumn{2}{|c|}{ UNIFAC-LL } \\
\hline & $\begin{array}{l}{\left[x_{s_{2}}^{(1)}\right.} \\
\left.x_{s_{2}}^{(2)}\right]\end{array}$ & $\begin{array}{l}\left(a_{s_{1}}^{(12)},\right. \\
\left.a_{s_{2}}^{(12)}\right)\end{array}$ & $\begin{array}{l}{\left[x_{s_{2}}^{(1)},\right.} \\
\left.x_{s_{2}}^{(2)}\right]\end{array}$ & $\begin{array}{l}\left(a_{s_{1}}^{(12)},\right. \\
\left.a_{s_{2}}^{(12)}\right)\end{array}$ & $\begin{array}{l}{\left[x_{s_{2}}^{(1)}\right.} \\
\left.x_{s_{2}}^{(2)}\right]\end{array}$ & $\begin{array}{l}\left(a_{s_{1}}^{(12)},\right. \\
\left.a_{s_{2}}^{(12)}\right)\end{array}$ \\
\hline $\mathrm{X} 2 / \mathrm{X} 4$ & $\begin{array}{l}{[1.969 \mathrm{e}-01} \\
4.554 \mathrm{e}-01]\end{array}$ & $\begin{array}{l}(9.196 \mathrm{e}-01, \\
7.236 \mathrm{e}-01)\end{array}$ & $\begin{array}{l}{[1.969 \mathrm{e}-01,} \\
4.554 \mathrm{e}-01]\end{array}$ & $\begin{array}{l}(9.196 \mathrm{e}-01, \\
7.236 \mathrm{e}-01)\end{array}$ & none & none \\
\hline $\mathrm{X} 2 / \mathrm{X} 5$ & $\begin{array}{l}{[7.732 \mathrm{e}-03,} \\
6.788 \mathrm{e}-01]\end{array}$ & $\begin{array}{l}(9.932 \mathrm{e}-01 \\
6.861 \mathrm{e}-01)\end{array}$ & $\begin{array}{l}{[6.545 \mathrm{e}-03,} \\
7.369 \mathrm{e}-01]\end{array}$ & $\begin{array}{l}(9.941 \mathrm{e}-01, \\
7.626 \mathrm{e}-01)\end{array}$ & none & none \\
\hline $\mathrm{X} 2 / \mathrm{X} 6$ & $\begin{array}{l}{[1.723 \mathrm{e}-04} \\
9.845 \mathrm{e}-01]\end{array}$ & $\begin{array}{l}(9.998 \mathrm{e}-01 \\
9.852 \mathrm{e}-01)\end{array}$ & $\begin{array}{l}{[1.723 \mathrm{e}-04} \\
9.845 \mathrm{e}-01]\end{array}$ & $\begin{array}{l}(9.998 \mathrm{e}-01 \\
9.852 \mathrm{e}-01)\end{array}$ & $\begin{array}{l}{[8.697 \mathrm{e}-03,} \\
4.805 \mathrm{e}-01]\end{array}$ & $\begin{array}{l}(9.928 \mathrm{e}-01, \\
5.585 \mathrm{e}-01)\end{array}$ \\
\hline $\mathrm{X} 2 / \mathrm{X}[7,8]$ & none & none & none & none & none & none \\
\hline $\mathrm{X} 3 / \mathrm{X} 4$ & $\begin{array}{l}{[4.277 \mathrm{e}-02,} \\
5.352 \mathrm{e}-01]\end{array}$ & $\begin{array}{l}(9.716 \mathrm{e}-01, \\
6.709 \mathrm{e}-01)\end{array}$ & $\begin{array}{l}{[4.277 \mathrm{e}-02,} \\
5.352 \mathrm{e}-01]\end{array}$ & $\begin{array}{l}(9.716 \mathrm{e}-01 \\
6.709 \mathrm{e}-01)\end{array}$ & none & none \\
\hline $\mathrm{X} 3 / \mathrm{X} 5$ & $\begin{array}{l}{[3.435 \mathrm{e}-03,} \\
6.581 \mathrm{e}-01]\end{array}$ & $\begin{array}{l}(9.968 \mathrm{e}-01 \\
7.113 \mathrm{e}-01)\end{array}$ & $\begin{array}{l}{[3.444 \mathrm{e}-03} \\
6.581 \mathrm{e}-01]\end{array}$ & $\begin{array}{l}(9.968 \mathrm{e}-01 \\
7.113 \mathrm{e}-01)\end{array}$ & none & none \\
\hline $\mathrm{X} 3 / \mathrm{X} 6$ & $\begin{array}{l}{[1.728 \mathrm{e}-04} \\
9.485 \mathrm{e}-01]\end{array}$ & $\begin{array}{l}(9.996 \mathrm{e}-01 \\
9.530 \mathrm{e}-01)\end{array}$ & $\begin{array}{l}{[1.728 \mathrm{e}-04} \\
9.485 \mathrm{e}-01]\end{array}$ & $\begin{array}{l}(9.996 \mathrm{e}-01 \\
9.530 \mathrm{e}-01)\end{array}$ & none & none \\
\hline $\mathrm{X} 3 / \mathrm{X}[7,8]$ & none & none & none & none & none & none \\
\hline $\mathrm{X} 4 / \mathrm{X}[5-8]$ & none & none & none & none & none & none \\
\hline X5/X6 & none & none & none & none & none & none \\
\hline $\mathrm{X} 5 / \mathrm{X} 7$ & $\begin{array}{l}\text { [5.367e-01, } \\
9.334 \mathrm{e}-01]\end{array}$ & $\begin{array}{l}(5.618 \mathrm{e}-01, \\
9.607 \mathrm{e}-01)\end{array}$ & $\begin{array}{l}{[4.528 \mathrm{e}-01} \\
9.465 \mathrm{e}-01]\end{array}$ & $\begin{array}{l}(6.518 \mathrm{e}-01, \\
9.653 \mathrm{e}-01)\end{array}$ & none & none \\
\hline $\mathrm{X} 5 / \mathrm{X} 8$ & $\begin{array}{l}{[5.941 \mathrm{e}-01,} \\
8.744 \mathrm{e}-01]\end{array}$ & $\begin{array}{l}(6.226 \mathrm{e}-01, \\
9.414 \mathrm{e}-01)\end{array}$ & $\begin{array}{l}{[4.925 \mathrm{e}-01,} \\
9.049 \mathrm{e}-01]\end{array}$ & $\begin{array}{l}(6.833 \mathrm{e}-01 \\
9.478 \mathrm{e}-01)\end{array}$ & none & none \\
\hline $\mathrm{X} 6 / \mathrm{X} 7$ & $\begin{array}{l}{[2.535 \mathrm{e}-02,} \\
9.983 \mathrm{e}-01]\end{array}$ & $\begin{array}{l}(9.768 \mathrm{e}-01, \\
9.983 \mathrm{e}-01)\end{array}$ & $\begin{array}{l}{[2.535 \mathrm{e}-02} \\
9.983 \mathrm{e}-01]\end{array}$ & $\begin{array}{l}(9.768 \mathrm{e}-01 \\
9.983 \mathrm{e}-01)\end{array}$ & none & none \\
\hline $\mathrm{X} 6 / \mathrm{X} 8$ & $\begin{array}{l}{[3.773 \mathrm{e}-02} \\
9.964 \mathrm{e}-01]\end{array}$ & $\begin{array}{l}(9.659 \mathrm{e}-01 \\
9.965 \mathrm{e}-01)\end{array}$ & $\begin{array}{l}{[3.772 \mathrm{e}-02,} \\
9.964 \mathrm{e}-01]\end{array}$ & $\begin{array}{l}(9.659 \mathrm{e}-01 \\
9.965 \mathrm{e}-01)\end{array}$ & $\begin{array}{l}{[3.581 \mathrm{e}-01,} \\
9.432 \mathrm{e}-01]\end{array}$ & $\begin{array}{l}(7.668 \mathrm{e}-01, \\
9.631 \mathrm{e}-01)\end{array}$ \\
\hline X7/X8 & none & none & none & none & none & none \\
\hline
\end{tabular}

phase diagrams with the binary systems water/X(1-8), $\mathrm{X} 5 / \mathrm{X} 7, \mathrm{X} 2 / \mathrm{X} 3, \mathrm{X} 8 / \mathrm{X} 6, \mathrm{X} 1 / \mathrm{X} 4$, which are the limiting cases of the four ternary systems when the concentration of one component in the system becomes negligible. We note that the phase diagrams for the binary systems presented in Fig. 1 are best viewed together with the phase diagrams for their corresponding ternary systems presented in Figs. 2-5. When combined, fine-scale phase structures near the phase space boundaries for the ternary systems can be revealed from the phase diagrams of the binary systems in a thermodynamically consistent fashion.

Figures $1 \mathrm{a}-\mathrm{i}$ show the computed phase diagrams in terms of the normalized GFE, $g_{n}$, and equilibrium activities for binary systems water/X(1-8), X5/X7, X2/X3, X8/X6, X1/X4. The two equilibrium phases are represented by red circles, and are connected by the solid tie-line. In Fig. 1a, for the water/X4 system the two equilibrium phases are located at organic mole fractions, $1.188 \times 10^{-7}$ and 0.8433 (as listed in Table 3), corresponding to the two locations at which the Gibbs tangent plane supports the graph of the normalized GFE. The interval $\left(0,1.188 \times 10^{-7}\right)$ on the $x$-axis corresponds to a one-phase region (not visible in the present scale) that consists of an essentially pure water phase with the organic mole fraction of X4 less than $1.188 \times 10^{-7}$. The interval $\left(1.188 \times 10^{-7}, 0.8433\right)$ on the $x$-axis corresponds to a two-phase region where an essentially pure water phase with the mole fraction of $\mathrm{X} 4$ being $1.188 \times 10^{-7}$ is in equilibrium with an organic phase with the mole fraction of $\mathrm{X} 4$ being 0.8433 , implying that the water activity in two-phase equilibrium is essentially equal to 1 (refer to Fig. $1 \mathrm{~b}$ and Table 3 ). The interval $(0.8433,1)$ on the $x$-axis corresponds to a onephase region that consists of a organic phase with the mole fraction of X4 exceeding 0.8433 . For the water/X3 system in the same figure, the region where a two-phase equilibrium is predicted by the model, located at the organic mole fractions 0.09365 and 0.3453 , is smaller compared to the twophase region for the water/X4 system. On the other hand, no two-phase equilibrium is predicted for the systems of water/X[1,2]. The activities of components 1 (i.e. water) and 2 (i.e. organic) are shown in Figs. $1 \mathrm{~b}$ and c.

In Fig. 1d, two-phase equilibria are predicted for all systems water/X(5-8). Phase separation occurs essentially over the entire range for the system water/X6, with the corresponding equilibrium water and X6 activities being essentially 1 (Table 3, Fig. 1e and Fig. 1f). The two-phase regions for the systems water/X $(5,7,8)$ are located in the intervals $\left(2.061 \times 10^{-12}, 0.8984\right),\left(3.351 \times 10^{-3}, 0.3655\right)$ and $\left(1.049 \times 10^{-3}, 0.4922\right)$, respectively, with the corresponding equilibrium water activity being essentially 1 (Table 3 and Fig. 1e). In Fig. 1g, phase separation again occurs over 
(a)

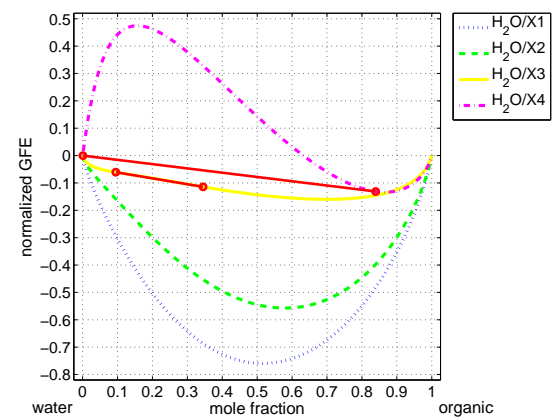

(d)

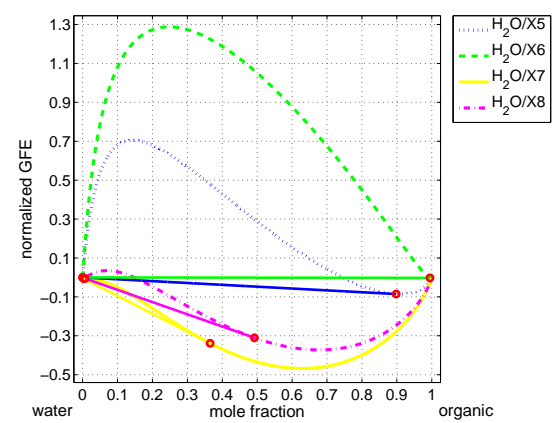

(g)

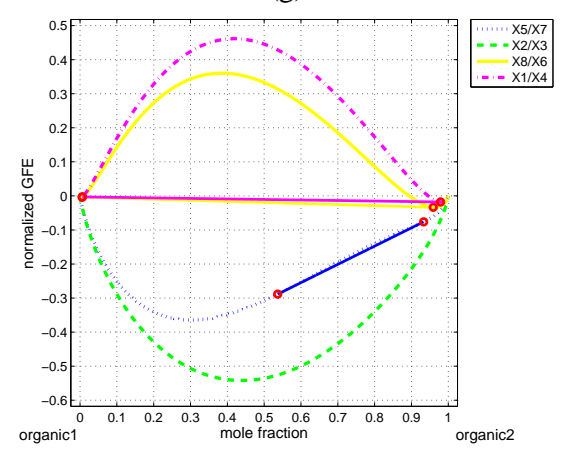

(b)

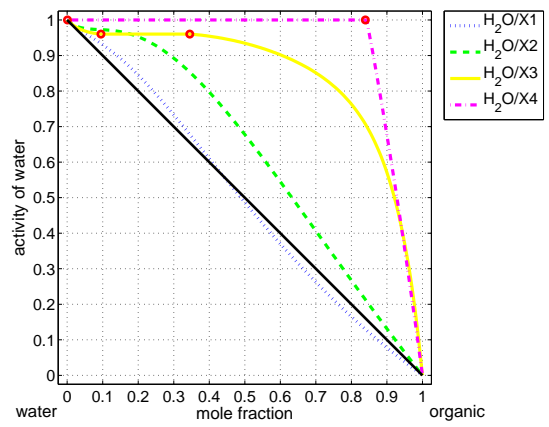

(e)

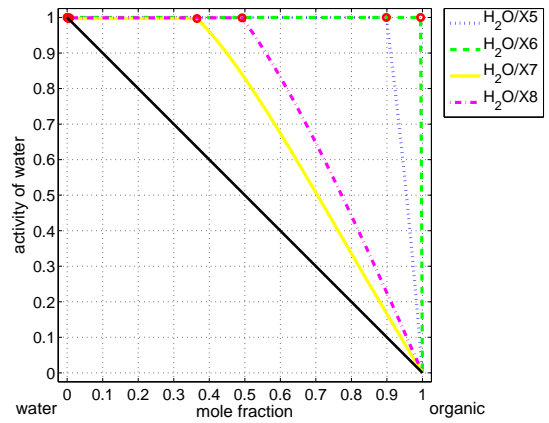

(h)

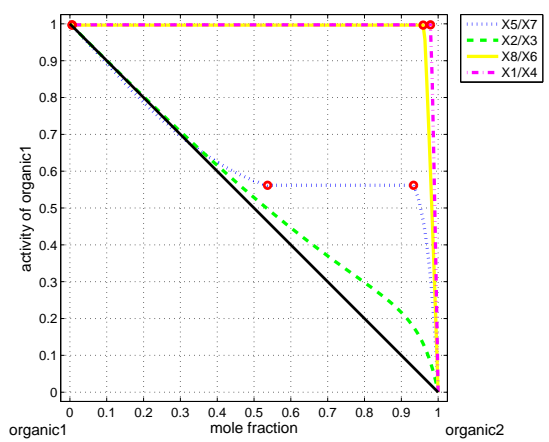

(c)

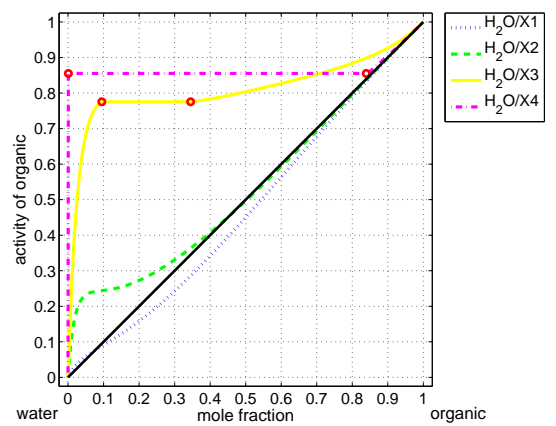

(f)

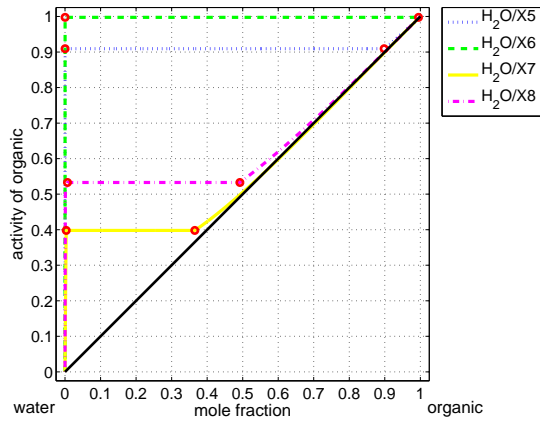

(i)

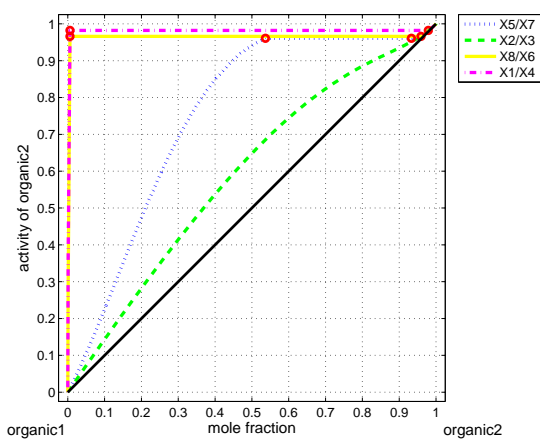

Fig. 1. Normalized GFE curves for all water/organic systems and two selected organic systems $\mathrm{s}_{1} / \mathrm{s}_{2}$, and their respective activities. Equilibrium two phase solutions (if any) are marked with circle symbols. The solid (-) line represents the tie lines. Normalized GFE curves are plotted as a function of mole fraction of organic component $\mathrm{s}_{2}$ for: (a) systems of water ( $\left.\mathrm{s}_{1}\right) / \mathrm{X}[1-4]\left(\mathrm{s}_{2}\right)$ at $298.15 \mathrm{~K}$; (b) the activity of water in systems of water/X[1-4] and (c) activity of X[1-4] for the systems of water/X[1-4]. (d) Systems of water/X[5-8] at 298.15 K. (e) The activity of water in systems of water/X[5-8] and (f) the activity of X[5-8]. (g) Systems of X5/X7, X2/X3, X8/X6, and X1/X4. (h) The activity of component $s_{1}$ for the $s_{1} / s_{2}$ system is shown in panel $(\mathrm{g})$, and (i) the activity of component $s_{2}$ for the $s_{1} / s_{2}$ system is shown in panel (h).

almost the entire mole faction range for systems $\mathrm{X} 1 / \mathrm{X} 4$ and X8/X6. The corresponding activities for each component in the system are essentially unity (shown in Figs. $1 \mathrm{~h}$ and i), indicating that $\mathrm{X} 1$ and $\mathrm{X} 4, \mathrm{X} 8$ and $\mathrm{X} 6$ are immiscible with each other. On the other hand, $\mathrm{X} 5$ and $\mathrm{X} 7$ are partially miscible, and $\mathrm{X} 2$ and $\mathrm{X} 3$ are fully miscible.

Figure 2 presents phase diagrams for the system water/1hexacosanol(X5)/pinic $\operatorname{acid}(\mathrm{X} 7)$ at $298.15 \mathrm{~K}$. This system typifies one consisting of a large alkane containing an alcohol group and an acidic terpene oxidation product, both in the presence of water. In Fig. 2a, the phase boundaries are marked with solid bold lines, and the dashed lines represent the two-phase tie lines. Three distinct two-phase regions (L2) bordering one three-phase region (L3) are predicted, as shown in Fig. 2a. The third two-phase region, which is a narrow strip bounded between the bottom edge of the triangular shaped L3 region and the $x$-axis, is of negligible size and is not visible at the scale of Fig. 2a, but can be deduced from the phase diagram of water/X7 in Fig. 1d. Contours of the activity of water, 1-hexacosanol, and pinic acid for the mixture 
Table 4. Three-phase equilibrium solutions for ternary systems.

\begin{tabular}{|c|c|c|c|c|c|c|c|c|c|}
\hline \multirow[b]{2}{*}{$\begin{array}{l}\text { system } \\
\left(s_{1} / s_{2} / s_{3}\right)\end{array}$} & \multicolumn{3}{|c|}{ UNIFAC } & \multicolumn{3}{|c|}{ UNIFAC-Peng } & \multicolumn{3}{|c|}{ UNIFAC-LL } \\
\hline & $\begin{array}{l}\left(x_{s_{2}}^{(1)},\right. \\
x_{s_{2}}^{(2)}, \\
\left.x_{s_{2}}^{(3)}\right)\end{array}$ & $\begin{array}{l}\left(x_{s_{3}}^{(1)},\right. \\
x_{s_{3}}^{(2)}, \\
\left.x_{s_{3}}^{(3)}\right)\end{array}$ & $\begin{array}{l}\left(a_{s_{1}}^{(123)}\right. \\
a_{s_{2}}^{(123)} \\
\left.a_{s_{3}}^{(123)}\right)\end{array}$ & $\begin{array}{c}\left(x_{s_{2}}^{(1)},\right. \\
x_{s_{2}}^{(2)}, \\
\left.x_{s_{2}}^{(3)}\right)\end{array}$ & $\begin{array}{l}\left(x_{s_{3}}^{(1)},\right. \\
x_{s_{3}}^{(2)}, \\
\left.x_{s_{3}}^{(3)}\right)\end{array}$ & $\begin{array}{c}\left(a_{s_{1}}^{(123)},\right. \\
a_{s_{2}}^{(123)}, \\
\left.a_{s_{3}}^{(123)}\right)\end{array}$ & $\begin{array}{l}\left(x_{s_{2}}^{(1)},\right. \\
x_{s_{2}}^{(2)}, \\
\left.x_{s_{2}}^{(3)}\right)\end{array}$ & $\begin{array}{l}\left(x_{s_{3}}^{(1)},\right. \\
x_{s_{3}}^{(2)}, \\
\left.x_{s_{3}}^{(3)}\right)\end{array}$ & $\begin{array}{l}\left(a_{s_{1}}^{(123)},\right. \\
a_{s_{2}}^{(123)}, \\
\left.a_{s_{3}}^{(123)}\right)\end{array}$ \\
\hline water/X1/X[2-8] & none & none & none & none & none & none & none & none & none \\
\hline water/X2/X[3-8] & none & none & none & none & none & none & none & none & none \\
\hline water/X3/X4 & $\begin{array}{l}(8.24 \mathrm{e}-02, \\
3.76 \mathrm{e}-01, \\
4.78 \mathrm{e}-01)\end{array}$ & $\begin{array}{l}(7.90 \mathrm{e}-06 \\
4.21 \mathrm{e}-01 \\
1.17 \mathrm{e}-02)\end{array}$ & $\begin{array}{l}(9.62 \mathrm{e}-01, \\
7.65 \mathrm{e}-01 \\
5.79 \mathrm{e}-01)\end{array}$ & $\begin{array}{l}(7.44 \mathrm{e}-02, \\
4.40 \mathrm{e}-01, \\
5.43 \mathrm{e}-01)\end{array}$ & $\begin{array}{l}(9.16 \mathrm{e}-06 \\
2.59 \mathrm{e}-01 \\
4.93 \mathrm{e}-02)\end{array}$ & $\begin{array}{l}(9.63 \mathrm{e}-01, \\
7.53 \mathrm{e}-01 \\
4.77 \mathrm{e}-01)\end{array}$ & $\begin{array}{l}(4.74 \mathrm{e}-02, \\
3.11 \mathrm{e}-01, \\
4.62 \mathrm{e}-01)\end{array}$ & $\begin{array}{l}(6.38 \mathrm{e}-07 \\
2.25 \mathrm{e}-03, \\
4.80 \mathrm{e}-01)\end{array}$ & $\begin{array}{l}(9.74 \mathrm{e}-01, \\
5.71 \mathrm{e}-01, \\
5.72 \mathrm{e}-01)\end{array}$ \\
\hline water/X3/X5 & $\begin{array}{l}(9.35 \mathrm{e}-02, \\
2.65 \mathrm{e}-01 \\
3.48 \mathrm{e}-01)\end{array}$ & $\begin{array}{l}(6.13 \mathrm{e}-09 \\
6.16 \mathrm{e}-01 \\
4.35 \mathrm{e}-05)\end{array}$ & $\begin{array}{l}(9.60 \mathrm{e}-01, \\
7.75 \mathrm{e}-01 \\
6.78 \mathrm{e}-01)\end{array}$ & $\begin{array}{l}(9.34 \mathrm{e}-02, \\
2.78 \mathrm{e}-01, \\
3.50 \mathrm{e}-01)\end{array}$ & $\begin{array}{l}(1.09 \mathrm{e}-08 \\
4.69 \mathrm{e}-01 \\
7.77 \mathrm{e}-05)\end{array}$ & $\begin{array}{l}(9.60 \mathrm{e}-01, \\
7.75 \mathrm{e}-01, \\
4.16 \mathrm{e}-01)\end{array}$ & $\begin{array}{l}(4.89 \mathrm{e}-02 \\
2.84 \mathrm{e}-01 \\
5.61 \mathrm{e}-01)\end{array}$ & $\begin{array}{l}(6.63 \mathrm{e}-11, \\
2.92 \mathrm{e}-05, \\
3.30 \mathrm{e}-01)\end{array}$ & $\begin{array}{l}(9.74 \mathrm{e}-01, \\
5.74 \mathrm{e}-01, \\
3.28 \mathrm{e}-01)\end{array}$ \\
\hline water/X3/X6 & $\begin{array}{l}(3.86 \mathrm{e}-02, \\
9.37 \mathrm{e}-02, \\
3.45 \mathrm{e}-01)\end{array}$ & $\begin{array}{l}(9.59 \mathrm{e}-01 \\
8.98 \mathrm{e}-12 \\
2.17 \mathrm{e}-07)\end{array}$ & $\begin{array}{l}(9.60 \mathrm{e}-01, \\
7.75 \mathrm{e}-01, \\
9.62 \mathrm{e}-01)\end{array}$ & $\begin{array}{l}(3.86 \mathrm{e}-02, \\
9.37 \mathrm{e}-02, \\
3.45 \mathrm{e}-01)\end{array}$ & $\begin{array}{l}(9.59 \mathrm{e}-01, \\
8.98 \mathrm{e}-12 \\
2.17 \mathrm{e}-07)\end{array}$ & $\begin{array}{l}(9.60 \mathrm{e}-01, \\
7.75 \mathrm{e}-01, \\
9.62 \mathrm{e}-01)\end{array}$ & $\begin{array}{l}(4.90 \mathrm{e}-02, \\
2.83 \mathrm{e}-01, \\
4.63 \mathrm{e}-01)\end{array}$ & $\begin{array}{l}(7.81 \mathrm{e}-14, \\
3.00 \mathrm{e}-07, \\
5.37 \mathrm{e}-01)\end{array}$ & $\begin{array}{l}(9.74 \mathrm{e}-01, \\
5.74 \mathrm{e}-01, \\
5.39 \mathrm{e}-01)\end{array}$ \\
\hline water/X3/X[7,8] & none & none & none & none & none & none & none & none & none \\
\hline water/X4/X[5-8] & none & none & none & none & none & none & none & none & none \\
\hline water/X5/X[6] & none & none & none & none & none & none & none & none & none \\
\hline water/X5/X7 & $\begin{array}{l}(3.40 \mathrm{e}-12 \\
2.33 \mathrm{e}-03 \\
6.09 \mathrm{e}-01)\end{array}$ & $\begin{array}{l}(3.35 \mathrm{e}-03 \\
3.72 \mathrm{e}-01 \\
2.19 \mathrm{e}-01)\end{array}$ & $\begin{array}{l}(9.97 \mathrm{e}-01, \\
6.71 \mathrm{e}-01 \\
3.96 \mathrm{e}-01)\end{array}$ & $\begin{array}{l}(2.42 \mathrm{e}-11, \\
1.81 \mathrm{e}-04, \\
5.82 \mathrm{e}-01)\end{array}$ & $\begin{array}{l}(8.56 \mathrm{e}-03 \\
2.09 \mathrm{e}-01 \\
1.05 \mathrm{e}-01)\end{array}$ & $\begin{array}{l}(9.94 \mathrm{e}-01, \\
5.11 \mathrm{e}-01, \\
1.91 \mathrm{e}-01)\end{array}$ & $\begin{array}{l}(3.86 \mathrm{e}-13 \\
8.46 \mathrm{e}-04 \\
4.51 \mathrm{e}-01)\end{array}$ & $\begin{array}{l}(4.14 \mathrm{e}-03 \\
3.55 \mathrm{e}-01 \\
4.24 \mathrm{e}-01)\end{array}$ & $\begin{array}{l}(9.96 \mathrm{e}-01, \\
4.81 \mathrm{e}-01, \\
4.40 \mathrm{e}-01)\end{array}$ \\
\hline water/X5/X8 & $\begin{array}{l}(2.06 \mathrm{e}-12, \\
1.28 \mathrm{e}-02, \\
5.84 \mathrm{e}-01)\end{array}$ & $\begin{array}{l}(1.03 \mathrm{e}-03 \\
5.02 \mathrm{e}-01 \\
2.57 \mathrm{e}-01)\end{array}$ & $\begin{array}{l}(6.85 \mathrm{e}-01, \\
5.22 \mathrm{e}-01 \\
9.99 \mathrm{e}-01)\end{array}$ & $\begin{array}{l}(4.95 \mathrm{e}-12, \\
6.93 \mathrm{e}-03, \\
5.31 \mathrm{e}-01)\end{array}$ & $\begin{array}{l}(1.54 \mathrm{e}-03, \\
3.97 \mathrm{e}-01 \\
1.62 \mathrm{e}-01)\end{array}$ & $\begin{array}{l}(9.99 \mathrm{e}-01, \\
4.87 \mathrm{e}-01, \\
3.74 \mathrm{e}-01)\end{array}$ & $\begin{array}{l}(2.20 \mathrm{e}-13 \\
9.90 \mathrm{e}-03 \\
3.90 \mathrm{e}-01)\end{array}$ & $\begin{array}{l}(1.06 \mathrm{e}-03, \\
5.17 \mathrm{e}-01, \\
4.76 \mathrm{e}-01)\end{array}$ & $\begin{array}{l}(9.99 \mathrm{e}-01, \\
5.49 \mathrm{e}-01 \\
5.95 \mathrm{e}-01)\end{array}$ \\
\hline water/X6/X7 & $\begin{array}{l}(2.12 \mathrm{e}-15 \\
3.26 \mathrm{e}-05 \\
9.87 \mathrm{e}-01)\end{array}$ & $\begin{array}{l}(3.38 \mathrm{e}-03 \\
3.66 \mathrm{e}-01 \\
9.66 \mathrm{e}-03)\end{array}$ & $\begin{array}{l}(9.97 \mathrm{e}-01, \\
9.88 \mathrm{e}-01, \\
3.98 \mathrm{e}-01)\end{array}$ & $\begin{array}{l}(7.85 \mathrm{e}-15, \\
8.97 \mathrm{e}-07, \\
9.93 \mathrm{e}-01)\end{array}$ & $\begin{array}{l}(8.56 \mathrm{e}-03, \\
2.08 \mathrm{e}-01, \\
4.57 \mathrm{e}-03)\end{array}$ & $\begin{array}{l}(9.94 \mathrm{e}-01, \\
9.93 \mathrm{e}-01 \\
1.91 \mathrm{e}-01)\end{array}$ & $\begin{array}{l}(2.11 \mathrm{e}-16 \\
1.72 \mathrm{e}-05 \\
7.67 \mathrm{e}-01)\end{array}$ & $\begin{array}{l}(4.15 \mathrm{e}-03, \\
3.51 \mathrm{e}-01, \\
2.28 \mathrm{e}-01)\end{array}$ & $\begin{array}{l}(9.96 \mathrm{e}-01, \\
7.82 \mathrm{e}-01, \\
4.41 \mathrm{e}-01)\end{array}$ \\
\hline water/X6/X8 & $\begin{array}{l}(1.17 \mathrm{e}-15 \\
2.72 \mathrm{e}-04 \\
9.78 \mathrm{e}-01)\end{array}$ & $\begin{array}{l}(1.05 \mathrm{e}-03 \\
4.93 \mathrm{e}-01 \\
1.91 \mathrm{e}-02)\end{array}$ & $\begin{array}{l}(9.99 \mathrm{e}-01, \\
9.80 \mathrm{e}-01, \\
5.33 \mathrm{e}-01)\end{array}$ & $\begin{array}{l}(1.37 \mathrm{e}-15, \\
8.73 \mathrm{e}-05, \\
9.84 \mathrm{e}-01)\end{array}$ & $\begin{array}{l}(1.56 \mathrm{e}-03, \\
3.90 \mathrm{e}-01 \\
1.33 \mathrm{e}-02)\end{array}$ & $\begin{array}{l}(9.99 \mathrm{e}-01, \\
9.85 \mathrm{e}-01, \\
3.80 \mathrm{e}-01)\end{array}$ & $\begin{array}{l}(1.08 \mathrm{e}-16 \\
2.72 \mathrm{e}-04 \\
8.50 \mathrm{e}-01)\end{array}$ & $\begin{array}{l}(1.08 \mathrm{e}-03, \\
4.99 \mathrm{e}-01 \\
1.46 \mathrm{e}-01)\end{array}$ & $\begin{array}{l}(9.99 \mathrm{e}-01, \\
8.74 \mathrm{e}-01, \\
6.03 \mathrm{e}-01)\end{array}$ \\
\hline water/X7/X8 & none & none & none & none & none & none & none & none & none \\
\hline $\mathrm{X}\{\mathrm{i} / \mathrm{j} / \mathrm{k}\}_{1 \leq i<j<k \leq 8}$ & none & none & none & none & none & none & none & none & none \\
\hline
\end{tabular}

are shown in Figs. 2b, c, and d, respectively. Although no experimental data are available to confirm existence of a three liquid-phase region in this system, three liquid phases are permissible by the Gibbs phase rule and are the most stable equilibrium solution.

For Fig. 2a, if one starts with a mole fraction of 1hexacosanol of 0.4 and increases the mole fraction of pinic acid from 0 to 0.6 (i.e. going across the phase diagram horizontally at a mole fraction of 1-hexacosanol of 0.4 ), the system starts within a L2 (two-liquid) region, where the mixtures separate along the tie-lines into two phases: a mixed organic phase with high concentration of 1-hexacosanol (mole fractions from 0.609 to 0.894 ), some pinic acid, and water (mole fraction about 0.1), and an almost pure water phase with negligible concentrations of the organics. When the mole fraction of pinic acid is greater than $\sim 0.16$, the L3 region starts, where the mixtures separate into three equilibrium phases: equilibrium phase 1 (an almost pure water phase) with mole fraction of 1-hexacosanol, $x_{s_{2}}^{(1)}=3.40 \times$ $10^{-12}$ and mole fraction of pinic acid $x_{s_{3}}^{(1)}=0.00335$, equilibrium phase 2 (mixed aqueous phase with $63 \%$ of water) with $x_{s_{2}}^{(2)}=0.00233$ and $x_{s_{3}}^{(2)}=0.372$, and equilibrium phase 3 (mixed organic phase dominated by 1-hexacosanol) with $x_{s_{2}}^{(3)}=0.609$ and $x_{s_{3}}^{(3)}=0.219$ (listed in Table 4). As the mole fraction of pinic acid passes $\sim 0.3$, the system enters another L2 region with the mixture separating along the tie-lines into two mixed organic phases, one of which includes high concentrations of both 1-hexacosanol and pinic acid with a small amount of water, and the other of which includes pinic acid and water with a small amount of 1-hexacosanol.

Phase diagrams for the system water/adipic $\operatorname{acid}(\mathrm{X} 2) /$ glutaraldehyde(X3) are shown in Fig. 3. The 
(a)

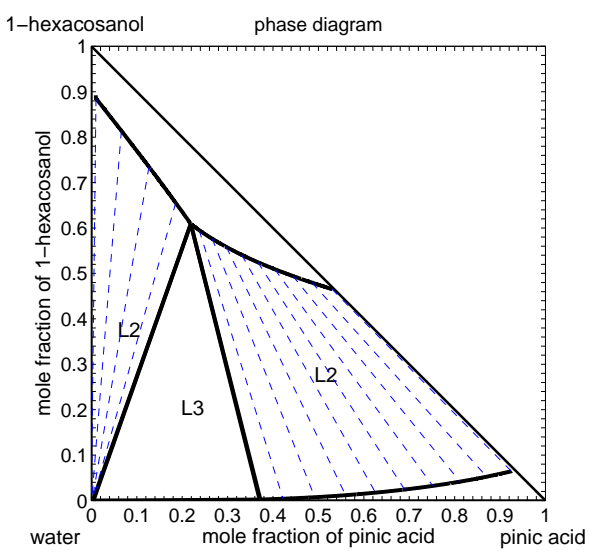

(c)

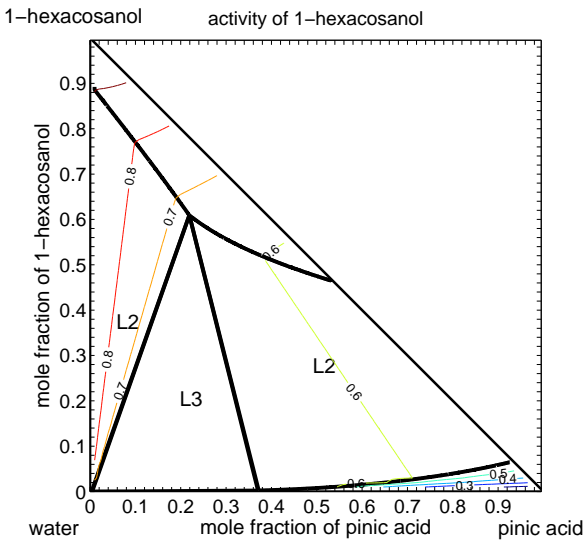

(b)

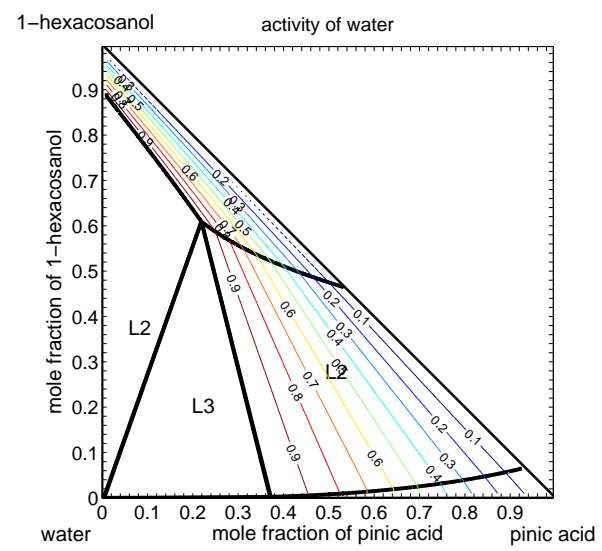

(d)

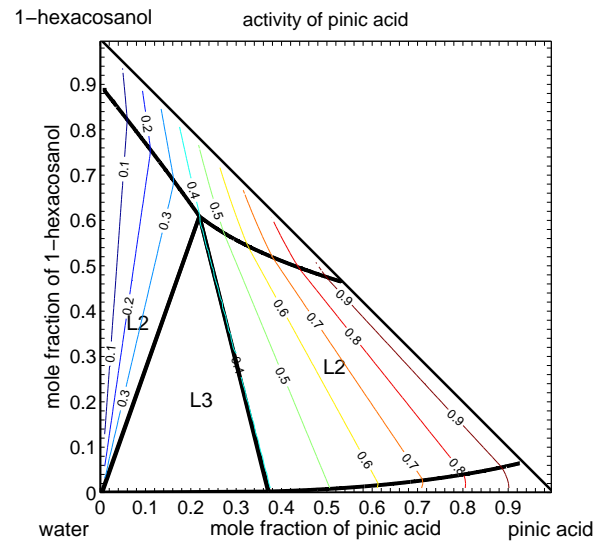

Fig. 2. Construction of the phase diagram for the system water/1-hexacosanol(X5)/pinic acid(X7) at $298.15 \mathrm{~K}$ with tracking of the presence of each distinct phase region. For each region the boundaries of which are marked with bold lines, the number of liquid phases at equilibrium is represented as L2 for two liquid phases and L3 for three liquid phases. (a) Liquid-liquid equilibrium prediction with two-phase tie lines represented by dashed lines. (b) Labels on the contours (-) indicate the value of the activity of water. (c) Labels on the contours (-) indicate the value of the activity of 1-hexacosanol. (d) Labels on the contours (-) indicate the value of the activity of pinic acid.

model predicts the system to be mostly a one-phase mixture, with a very small two-phase region. A three-phase equilibrium does not exist in this system.

Figure 4 presents the phase diagram for the water/pinonic $\operatorname{acid}(\mathrm{X} 8) /$ nonacosane(X6) system. A three-phase region (L3) is predicted in between three two-phase (L2) regions. Again, a third two-phase region, which is a narrow strip bounded between the left edge of the triangular shaped L3 region and the $y$-axis, is of negligible size and is not visible at the scale of Fig. 4a, but can be deduced from the phase diagram of water/X8 in Fig. 1d. Figure 5 presents the phase diagram for water/2-hydroxy-glutaric acid(X1)/palmitic acid(X4). The system is predicted to be largely a two-phase mixture, bounded by a small one-phase region at a mole fraction of palmitic acid above 0.85 and a mole fraction of 2-hydroxyglutaric acid approaching 0 and a one-phase region of negli- gible size, which is a narrow strip bounded between the left edge of the L2 region and the $y$-axis, and is not visible at the scale of Fig. 5, but can be deduced from the phase diagram of water/X1 in Fig. 1a. There is no three-phase equilibrium predicted for the system. The sensitivity of the predicted phase equilibrium to UNIFAC-Peng and UNIFAC-LL parameters for the ternary system water/1-hexacosanol/pinic acid is illustrated in Figs. 6a and b. By comparing Figs. 6 and $2 \mathrm{a}$, the overall change of the liquid phase equilibrium prediction by UNIFAC-Peng and UNIFAC-LL can be assessed. One would expect that UNIFAC-LL should be most accurate for the condensed phase calculation in this study, as the UNIFAC-LL parameters have been determined using liquidliquid equilibrium data. Although UNIFAC parameters were determined using vapor-liquid equilibrium data, it is the most widely used set of parameters, allowing comparison between 
(a)

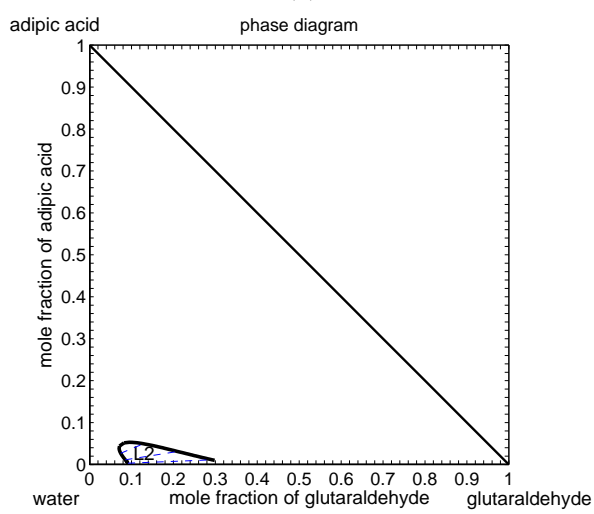

(c)

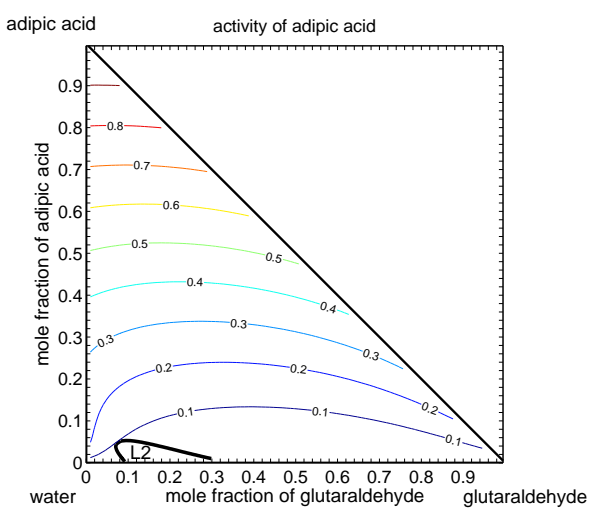

(b)

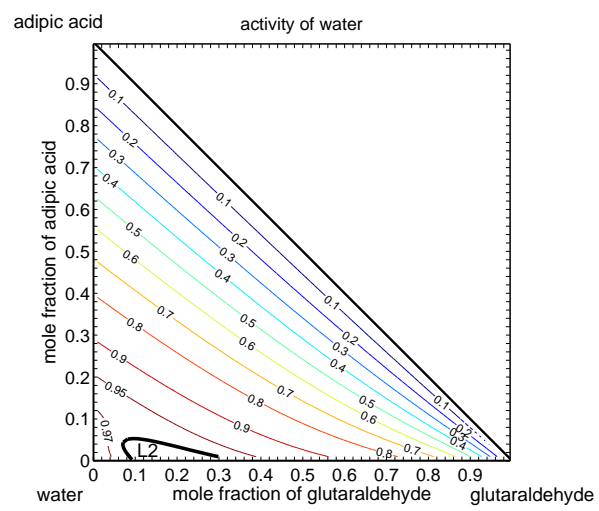

(d)

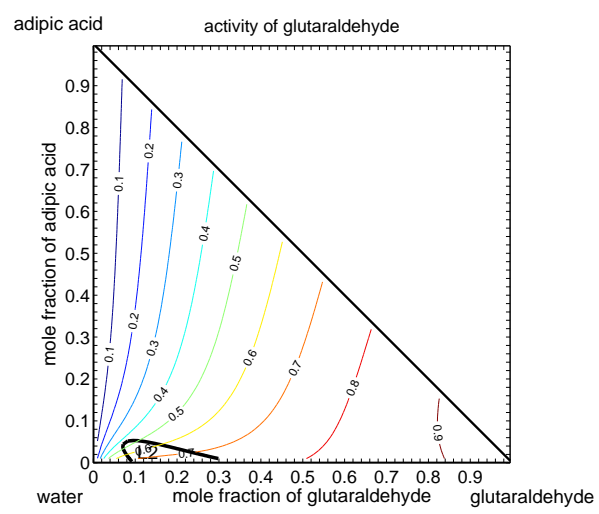

Fig. 3. Construction of the phase diagram for the system water/adipic acid(X2)/glutaraldehyde(X3) at $298.15 \mathrm{~K}$ with tracking of the presence of each distinct phase region. For each region the boundaries of which are marked with bold lines, the number of liquid phases at equilibrium is represented as L2 for two liquid phases and L3 for three liquid phases. (a) Liquid-liquid equilibrium prediction with two-phase tie lines represented by dashed lines. (b) Labels on the contours (-) indicate the value of the activity of water. (c) Labels on the contours (-) indicate the value of the activity of adipic acid. (d) Labels on the contours (-) indicate the value of the activity of glutaraldehyde.

different models. We return to a more in-depth analysis of the sensitivity to the choice of activity coefficient model in Sect. 5.

\section{Effects of organic phase equilibria on inorganic deli- quescence}

The inorganic system that has been most widely studied with respect to atmospheric gas-aerosol equilibrium and aerosol state is that of sulfate, nitrate, ammonium, and water. Particles consisting of these species can be fully aqueous, fully crystalline, or consist of liquid-solid mixtures, depending on the relative concentrations of the components, $\mathrm{RH}$, and temperature. An important question is the extent to which the presence of organic species influences the deliquescence and efflorescence phase transitions of salts in this system. We now present results of application of UHAERO to computation of the inorganic phase diagram of this system in the presence of organic species. To construct del- iquescence phase diagrams of the five-component system $\mathrm{SO}_{4}^{2-} / \mathrm{NO}_{3}^{-} / \mathrm{NH}_{4}^{+} / \mathrm{H}^{+} / \mathrm{H}_{2} \mathrm{O}$, we use the $X$ and $Y$ composition coordinates as in Amundson et al. (2006c) and define:

$$
\begin{aligned}
& X=\text { Ammonium Fraction }=\frac{b_{\mathrm{NH}_{4}^{+}}}{b_{\mathrm{NH}_{4}^{+}}+b_{\mathrm{H}^{+}}}, \\
& Y=\text { Sulfate Fraction }=\frac{b_{\mathrm{SO}_{4}^{2-}}}{b_{\mathrm{SO}_{4}^{2-}}+b_{\mathrm{NO}_{3}^{-}}},
\end{aligned}
$$

where the system feeds $b_{\mathrm{SO}_{4}^{2-}}, b_{\mathrm{NO}_{3}^{-}}, b_{\mathrm{NH}_{4}^{+}}$, and $b_{\mathrm{H}^{+}}$are subject to the constraint of electroneutrality. Thus, for a fixed $(X, Y)$ coordinate, we can define a non-unique feed composition as $b_{\mathrm{SO}_{4}^{2-}}=\frac{Y}{1+Y}, b_{\mathrm{NO}_{3}^{-}}=\frac{1-Y}{1+Y}, b_{\mathrm{NH}_{4}^{+}}=X$, and $b_{\mathrm{H}^{+}}=1-X$.

To facilitate the computation of the boundaries in deliquescence phase diagrams, we also introduce the fractions

$$
f_{\mathrm{NH}_{4}^{+}}=\frac{b_{\mathrm{NH}_{4}^{+}}}{b_{\mathrm{NH}_{4}^{+}}+b_{\mathrm{H}^{+}}+(1+Y) b_{\mathrm{H}_{2} \mathrm{O}}},
$$


(a)

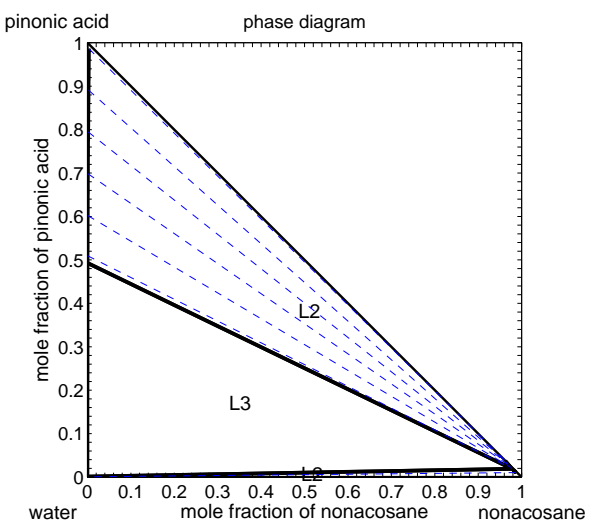

(c)

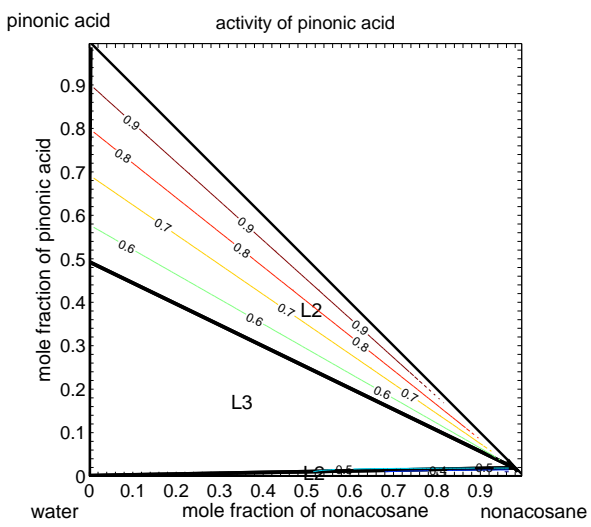

(b)

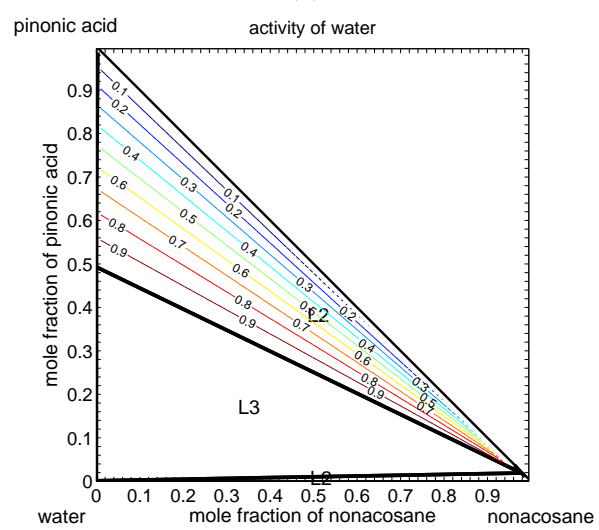

(d)

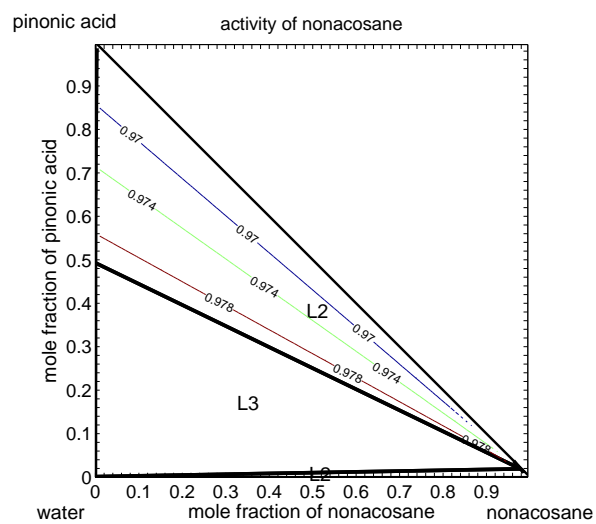

Fig. 4. Construction of the phase diagram for the system water/pinonic acid(X8)/nonacosane(X6) at $298.15 \mathrm{~K}$ with tracking of the presence of each distinct phase region. For each region the boundaries of which are marked with bold lines, the number of liquid phases at equilibrium is represented as L2 for two liquid phases and L3 for three liquid phases. (a) Liquid-liquid equilibrium prediction with two-phase tie lines represented by dashed lines. (b) Labels on the contours (-) indicate the value of the activity of water. (c) Labels on the contours (-) indicate the value of the activity of pinonic acid. (d) Labels on the contours (-) indicate the value of the activity of nonacosane.

$$
f_{\mathrm{H}^{+}}=\frac{b_{\mathrm{H}^{+}}}{b_{\mathrm{NH}_{4}^{+}}+b_{\mathrm{H}^{+}}+(1+Y) b_{\mathrm{H}_{2} \mathrm{O}}}
$$

which, together with $f_{\mathrm{H}_{2} \mathrm{O}}=1-\left(f_{\mathrm{NH}_{4}^{+}}+f_{\mathrm{H}^{+}}\right)$, are the barycentric coordinates of the unit triangle with vertices $(1+Y) \mathrm{H}_{2} \mathrm{O}, \mathrm{NH}_{4}^{+}$and $\mathrm{H}^{+}$. Thus, for a fixed $Y$, the fraction coordinate $\left(f_{\mathrm{NH}_{4}^{+}}, f_{\mathrm{H}^{+}}, f_{\mathrm{H}_{2} \mathrm{O}}\right)$ gives $X=\frac{f_{\mathrm{NH}_{4}^{+}}}{f_{\mathrm{NH}_{4}^{+}}+f_{\mathrm{H}^{+}}}$and $b_{\mathrm{H}_{2} \mathrm{O}}=\frac{1}{1+Y} \frac{f_{\mathrm{H}_{2} \mathrm{O}}}{1-f_{\mathrm{H}_{2} \mathrm{O}}}$. Therefore, the two-dimensional (2-D) phase diagrams for fixed $Y$ values can be generated in two coordinate systems: $(X, \mathrm{RH})$ and $\left(f_{\mathrm{H}^{+}}, f_{\mathrm{NH}_{4}^{+}}\right)$, which can be chosen on the basis of computational or graphic convenience.

For the system that includes the organic species $\mathrm{ORG}_{1}$, $\ldots, \mathrm{ORG}_{n_{o}}$ with feeds $b_{\mathrm{ORG}_{1}}, \cdots, b_{\mathrm{ORG}_{n_{o}}}$, we introduce the fractions $f_{\mathrm{ORG}_{2}}, \ldots, f_{\mathrm{ORG}_{n_{o}}}$

$f_{\mathrm{ORG}_{2}}=\frac{b_{\mathrm{ORG}_{2}}}{\sum_{i=1}^{n_{o}} b_{\mathrm{ORG}_{i}}}, \quad \cdots, \quad f_{\mathrm{ORG}_{n_{o}}}=\frac{b_{\mathrm{ORG}_{n_{o}}}}{\sum_{i=1}^{n_{o}} b_{\mathrm{ORG}_{i}}}$, which, together with $f_{\mathrm{ORG}_{1}}=1-\left(f_{\mathrm{ORG}_{2}}+\cdots+f_{\mathrm{ORG}_{n_{o}}}\right)$, are the barycentric coordinates of the $\left(n_{o}-1\right)$-dimensional unit simplex with vertices $\mathrm{ORG}_{1}, \ldots, \mathrm{ORG}_{n_{o}}$. We also need to specify the organic/inorganic mixing ratio $\alpha$,

$\alpha=\frac{\sum_{i=1}^{n_{o}} b_{\mathrm{ORG}_{i}}}{\sum_{i=1}^{n_{i}} b_{\mathrm{INORG}_{i}}+\sum_{i=1}^{n_{o}} b_{\mathrm{ORG}_{i}}}$,

where $\sum_{i=1}^{n_{i}} b_{\mathrm{INORG}_{i}}=b_{\mathrm{NH}_{4}^{+}}+b_{\mathrm{H}^{+}}+b_{\mathrm{SO}_{4}^{2-}}+b_{\mathrm{NO}_{3}^{-}}=\frac{2+Y}{1+Y}$. Thus, for a fixed $Y$, the ratio $\alpha$ and the fraction coordinate $\left(f_{\mathrm{ORG}_{1}}, \ldots, f_{\mathrm{ORG}_{n_{o}}}\right)$ give $b_{\mathrm{ORG}_{1}}=f_{\mathrm{ORG}_{1}} \frac{\alpha}{1-\alpha} \frac{2+Y}{1+Y}, \ldots$, $b_{\mathrm{ORG}_{n_{o}}}=f_{\mathrm{ORG}_{n_{o}}} \frac{\alpha}{1-\alpha} \frac{2+Y}{1+Y}$.

Figures $7 \mathrm{a}$ and $7 \mathrm{~b}$ show the computed phase diagrams in the $(X, \mathrm{RH})$ coordinate, with tracking of the presence of each solid phase, for the system $\left(\mathrm{NH}_{4}\right)_{2} \mathrm{SO}_{4} / \mathrm{H}_{2} \mathrm{SO}_{4} / \mathrm{NH}_{4} \mathrm{NO}_{3} / \mathrm{HNO}_{3} / \mathrm{H}_{2} \mathrm{O}$ at $298.15 \mathrm{~K}$ and fixed sulfate fractions $Y=1$ and 0.85 , respectively. For each region of space whose boundaries are marked with bold lines, the existing solid phases at equilibrium are represented, 
(a)

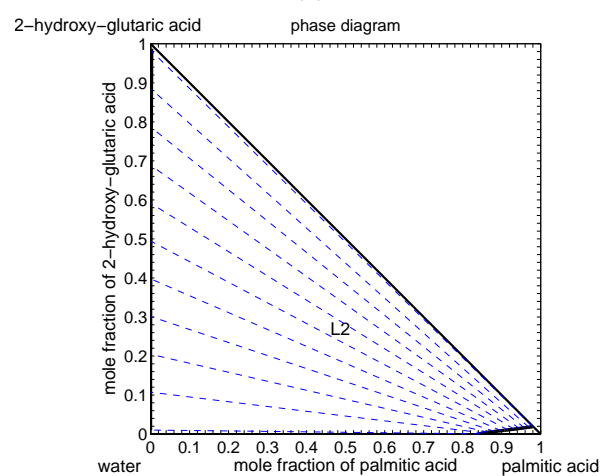

(c)

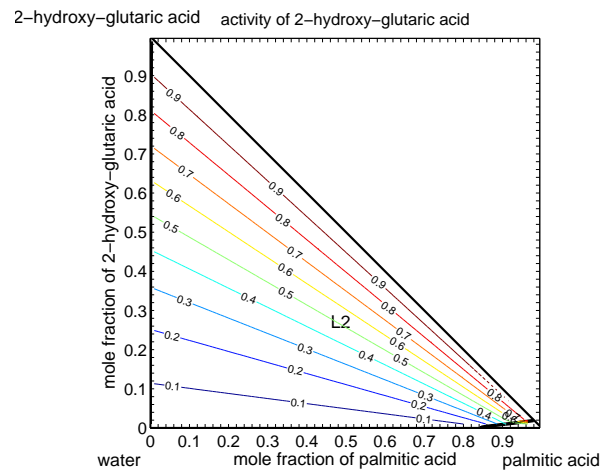

(b)

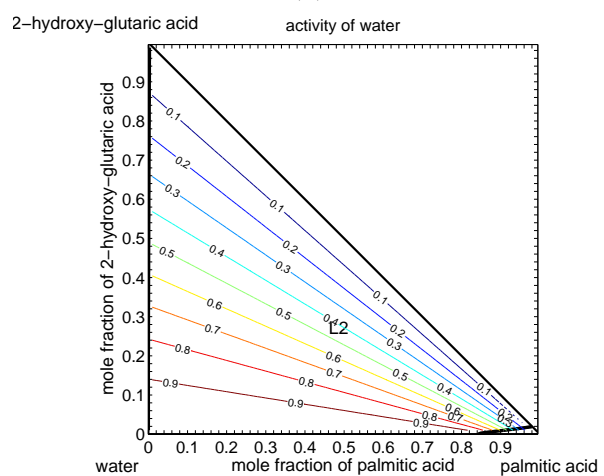

(d)

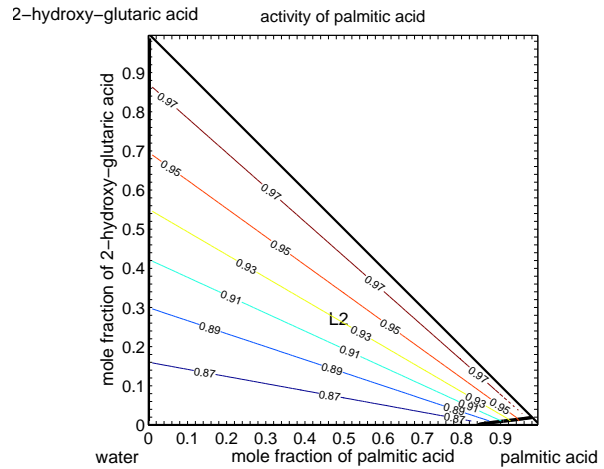

Fig. 5. Construction of the phase diagram for the system water/2-hydroxy-glutaric acid(X1)/palmitic acid(X4) at $298.15 \mathrm{~K}$ with tracking of the presence of each distinct phase region. For each region the boundaries of which are marked with bold lines, the number of liquid phases at equilibrium are represented as L2 for two liquid phases and L3 for three liquid phases. (a) Liquid-liquid equilibrium prediction with two-phase tie lines represented by dashed lines. (b) Labels on the contours (-) indicate the value of the activity of water. (c) Labels on the contours (-) indicate the value of the activity of 2-hydroxy-glutaric acid. (d) Labels on the contours (-) indicate the value of the activity of palmitic acid.

where the seven possible solid phases are labeled as $\mathrm{A}$ through $\mathrm{G}$. A denotes ammonium sulfate, $\left(\mathrm{NH}_{4}\right)_{2} \mathrm{SO}_{4}(\mathrm{AS})$; $\mathrm{B}$ denotes letovicite, $\left(\mathrm{NH}_{4}\right)_{3} \mathrm{H}\left(\mathrm{SO}_{4}\right)_{2}$ (LET); $\mathrm{C}$ denotes ammonium bisulfate, $\mathrm{NH}_{4} \mathrm{HSO}_{4}$ (AHS); D denotes ammonium nitrate, $\mathrm{NH}_{4} \mathrm{NO}_{3}(\mathrm{AN})$; $\mathrm{E}$ denotes the mixed salt, $2 \mathrm{NH}_{4} \mathrm{NO}_{3} \cdot\left(\mathrm{NH}_{4}\right)_{2} \mathrm{SO}_{4}$ (2AN.AS); $\mathrm{F}$ denotes the mixed salt, $3 \mathrm{NH}_{4} \mathrm{NO}_{3} \cdot\left(\mathrm{NH}_{4}\right)_{2} \mathrm{SO}_{4}(3 \mathrm{AN} \cdot \mathrm{AS})$; and $\mathrm{G}$ denotes the mixed salt of ammonium nitrate and ammonium bisulfate, $\mathrm{NH}_{4} \mathrm{NO}_{3} \cdot \mathrm{NH}_{4} \mathrm{HSO}_{4}$ (AN.AHS). In Fig. 7a, for the regions labeled as $\mathrm{AB}$ and $\mathrm{BC}$, the system is fully crystalline and consists of the two solid phases $\mathrm{A}+\mathrm{B}$ and $\mathrm{B}+\mathrm{C}$, the mutual deliquescence RHs of which are $68.57 \%$ and $36.65 \%$. In Fig. 7b, for the regions labeled as AB and numbered as 1 through 7 , the system consist of aqueous-solid mixtures, where the two solid phases at equilibrium are $\mathrm{A}+\mathrm{B}, \mathrm{A}+\mathrm{E}, \mathrm{B}+\mathrm{E}, \mathrm{B}+\mathrm{F}, \mathrm{B}+\mathrm{D}$, $\mathrm{B}+\mathrm{G}, \mathrm{B}+\mathrm{C}$, and $\mathrm{C}+\mathrm{G}$, respectively; for the regions labeled as $\mathrm{ABE}, \mathrm{BEF}, \mathrm{BDF}, \mathrm{BDG}, \mathrm{BCG}$, the system is fully crystalline and consists of the three solid phases $\mathrm{A}+\mathrm{B}+\mathrm{E}, \mathrm{B}+\mathrm{E}+\mathrm{F}$, $\mathrm{B}+\mathrm{D}+\mathrm{F}, \mathrm{B}+\mathrm{D}+\mathrm{G}, \mathrm{B}+\mathrm{C}+\mathrm{G}$ whose mutual deliquescence $\mathrm{RHs}$ are $56.31 \%, 53.21 \%, 43.84 \%, 35.89 \%, 29.65 \%$. Labels on the contours (-) present the relative water content in the system as a function of $X$ and $\mathrm{RH}$. The relative water content is defined as the ratio $\frac{b_{\mathrm{H}_{2} \mathrm{O}}}{\sum_{i=1}^{n_{i}} b_{\mathrm{INORG}_{i}}}$ of the water content $b_{\mathrm{H}_{2} \mathrm{O}}$ at a specific $\mathrm{RH}$ and $(X, Y)$ composition with respect to the inorganic content $\sum_{i=1}^{n_{i}} b_{\mathrm{INORG}_{i}}$ of the same $(X, Y)$ composition at the "dry-state".

For Fig. 7a, if one starts at an ammonium fraction, $X=0.6$ and increases RH from 0 to 80 (i.e. going up the phase diagram vertically at $X=0.6)$, as represented by the solid red deliquescence curve (a baseline result labeled by (0)) in Fig. 10a, the system starts with a fully crystalline two solid mixture of $\mathrm{B}\left(\left(\mathrm{NH}_{4}\right)_{3} \mathrm{H}\left(\mathrm{SO}_{4}\right)_{2}\right)$ (with $40 \%$ of mole fraction) and $\mathrm{C}\left(\mathrm{NH}_{4} \mathrm{HSO}_{4}\right)$ (with $60 \%$ of mole fraction). At $\mathrm{RH}$ $=36.6 \%$, solid $\mathrm{C}$ fully dissolves and the relative water content in the system promptly takes the value of 0.34 , then the system consists of an aqueous electrolyte solution of $\mathrm{B}$ and $\mathrm{C}$ in liquid-solid equilibrium with solid $\mathrm{B}$, where the relative water content is labeled on the contours in Fig. 7a or given in Fig. 10a. When $\mathrm{RH}$ reaches $63.8 \%$, with the relative water content being 1.44 , the system passes the boundary where 
(a)

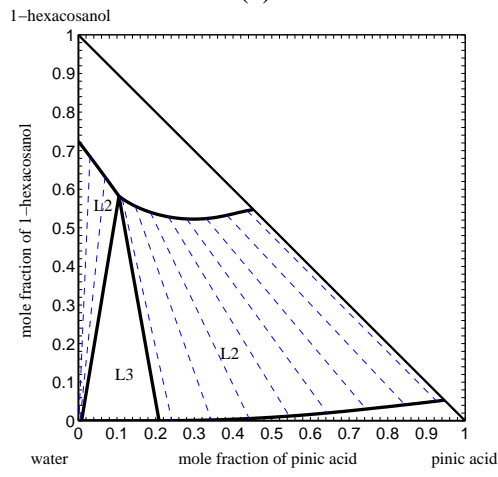

(b)

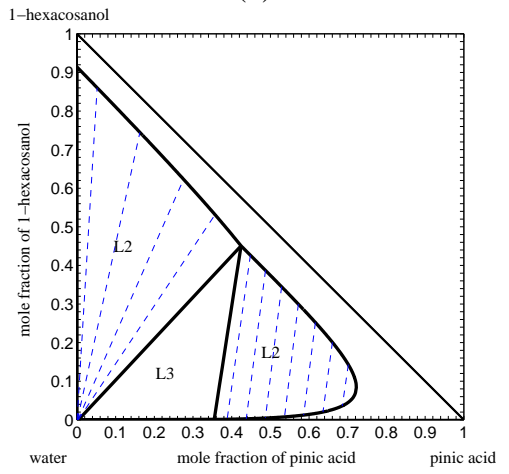

Fig. 6. Construction of the phase diagram for the system water/1-hexacosanol(X5)/pinic acid(X7) at $298.15 \mathrm{~K}$ with two different sets of UNIFAC parameters: (a) UNIFAC-Peng parameters, (b) UNIFAC-LL parameters.

solid B fully dissolves and the system changes into a singlephase aqueous solution. Similarly for Fig. 7b, as represented by the solid red deliquescence curve (a baseline result labeled by $(0))$ in Fig. 10b, now with a sulfate fraction $Y=0.85$, the system starts with a fully crystalline three solid mixture of $\mathrm{B}(13.3 \%)+\mathrm{C}(56.7 \%)+\mathrm{G}\left(\mathrm{NH}_{4} \mathrm{NO}_{3} \cdot \mathrm{NH}_{4} \mathrm{HSO}_{4}\right)(40 \%)$ at $X=0.6$ and $\mathrm{RH}=0$. At $\mathrm{RH}=29.7 \%$, solid $\mathrm{G}$ fully dissolves and the relative water content in the system promptly takes the value of 0.19 , then the system enters the region labeled 6 in Fig. 7b or labeled BC in Fig. 10b, where the aqueous solution is in liquid-solid equilibrium with two solids $\mathrm{B}+\mathrm{C}$. The system passes the boundary at $\mathrm{RH}=31.6 \%$ with the relative water content being $0.29, \mathrm{C}$ dissolves and it is now an aqueous solution in equilibrium with a single solid B. When RH reaches $58.5 \%$, the relative water content increases to 1.16 and the system becomes a single-phase aqueous solution.

Figures 8 and 9 show the corresponding deliquescence phase diagrams of $\left(\mathrm{NH}_{4}\right)_{2} \mathrm{SO}_{4} / \mathrm{H}_{2} \mathrm{SO}_{4} / \mathrm{NH}_{4} \mathrm{NO}_{3} / \mathrm{HNO}_{3} / \mathrm{H}_{2} \mathrm{O}$ when the system also includes two organic species, with sulfate fractions $(Y)$ of 1 and 0.85 . In the presence of organic species, the system can exhibit a mixture of multiple liquid and solid phases, depending on the relative composition of inorganic and organic species, RH, and temperature. However, a fully crystalline state of the system is not permissible. Each region that is marked with bold dashed lines delineates the existing liquid phases at equilibrium. The regions of one liquid phase, two liquid phases, and three liquid phases at equilibrium are labeled as L1, L2 and L3, respectively. Labels on the contours represent the relative water content. The bold dashed lines separating different liquid regions are contours of the relative water content taking a value given on the side of the figures.

Figure 8a shows the phase diagram including 1hexacosanol $\left(\mathrm{ORG}_{1}\right)$ and pinic acid $\left(\mathrm{ORG}_{2}\right)$ with the organic/inorganic mixing ratio $\alpha=0.2$ and the organic fractions $f_{\mathrm{ORG}_{1}}=0.5$ and $f_{\mathrm{ORG}_{2}}=0.5$. The molar mixing ratio of $\alpha=0.2$ corresponds approximately to the organic/inorganic mass mixing ratio of $65 \%$. Labels on the contours (-) present the relative water content (defined as the ratio $\frac{b_{\mathrm{H}_{2} \mathrm{O}}}{\sum_{i=1}^{n_{i}} b_{\mathrm{INORG}_{i}}}$ ) as a function of $X$ and $\mathrm{RH}$. The bold dashed lines separating different liquid regions are contours of the relative water content, with the values of 0.171 and 0.00974 . Region L 3 covers the fully liquid region and the regions of one solid phase at equilibrium. Region L3 consists of one aqueous phase and two organic phases, where the organic contribution to the activity of water $a_{w}^{(o)}$ is constant and $a_{w}^{(o)}=0.997=1-\frac{3}{1000}(\mathrm{Ta}-$ ble 4, UNIFAC column and water/X5/X7 row). Thus, the locations of contours of the water content in regions L3 are shifted three per thousand in the upward direction, compared to the locations of the corresponding contours in Fig. 7a where the system only includes inorganic species. In the L3 region, the addition of organic species has a negligible effect on the hygroscopic properties of the inorganic electrolytes; the phase diagram and water uptake in this region are almost identical in the presence and absence of organics (Fig. 7a). However, for most of the two solid regions, the phase diagram and water uptake are quite different as compared to those of the system without organics. L2 covers mostly the two-solids region, and it consists of two liquid (water + organics) phases in equilibrium with two solids $(\mathrm{A}+\mathrm{B}$ or $\mathrm{B}+\mathrm{C})$. The system consists of one liquid (water + organics) phase in equilibrium with two solids in the region that L1 covers. The original fully crystalline phase no longer exists owing to the presence of organics. Also, instead of a straight horizontal line corresponding to the mutual DRH (Fig. 7a), the "deliquescence" RH is now curved (Figs. 8 and 9). Due to the presence of organics, the originally crystalline system now is in equilibrium with at least one liquid phase. The water content in the system is not negligible and increases with RH. Salts "deliquescence" at a value of RH, with the water content now also a function of the ammonium fraction, causing the curving of the boundaries. If a similar analysis is carried for Fig. 8a as that for Fig. 7a, as represented by the dashed 
(a)

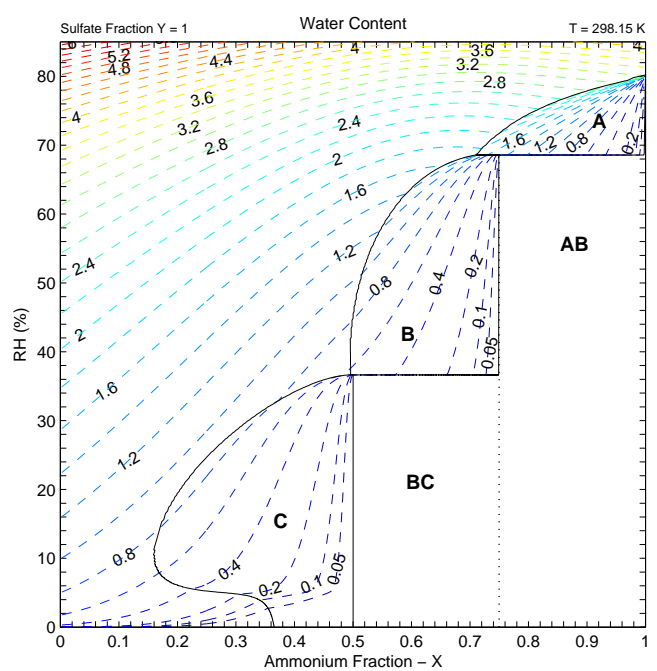

(b)

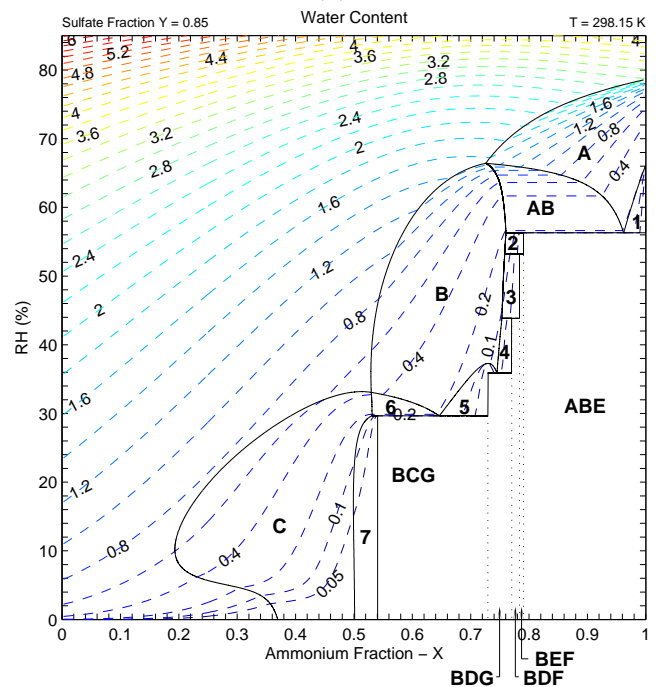

Fig. 7. Construction of the phase diagram for the system $\left(\mathrm{NH}_{4}\right)_{2} \mathrm{SO}_{4} / \mathrm{H}_{2} \mathrm{SO}_{4} / \mathrm{NH}_{4} \mathrm{NO}_{3} / \mathrm{HNO}_{3} / \mathrm{H}_{2} \mathrm{O}$ with the sulfate fraction: (a) $Y=1$, (b) $Y=0.85$, at $298.15 \mathrm{~K}$ with tracking of the presence of each phase. For each region the boundaries of which are marked with bold lines, the existing phases at equilibrium are represented. For the regions numbered as 1 through 7 , the existing phases at equilibrium are $\mathrm{AE}, \mathrm{BE}, \mathrm{BF}$, $\mathrm{BD}, \mathrm{BG}, \mathrm{BC}$, and CG, respectively. Labels on the dashed contours present the relative water content.

green curve and the first row of pie charts (labeled by (1)) in Fig. $10 \mathrm{a}$, the system at $X=0.6$ starts at $\mathrm{RH}=0$ in a $\mathrm{L} 1$ region, where there is a single liquid phase mixed of organics (1-hexacosanol and pinic acid) + little water (as RH is low) with some dissolved ions of $\mathrm{B}$ and $\mathrm{C}$ in equilibrium with the solids B and C. At RH $=6.2 \%$, the system crosses the phase boundary between $\mathrm{L} 1$ and L2 (indicated by a dashed line with the relative water content being 9.74e-03), then the system consists of two mixed organic + water phases with some dissolved ions B and C, and two solid phases B and C that are in equilibrium with the two liquid phases. When the RH reaches $36.5 \%$ (a decrease of 0.1 compared to the baseline value of $36.6 \%$ in (0)), solid $\mathrm{C}$ fully dissolves and the relative water content in the system promptly takes the value of 0.34 , then the system crosses the phase boundary between L2 and L3 (indicated by a dashed line with the relative water content being $1.71 \mathrm{e}-01$ ). Within the L3 region, the system consists of two organic phases (each containing some amount of water and dissolved ions B and C) and an aqueous phase (with some amount of organics and dissolved ions B and C), which are all in equilibrium with solid B. As RH increases to $63.6 \%$ (a decrease of 0.2 compared to the baseline value of $63.8 \%$ in (0)), B dissolves and the system is in a three liquid phase equilibrium (two organic phases with some amount of water and dissolved ions and an aqueous phase with some amount of organics and dissolved ions). No solid salt is present in system within the $\mathrm{L} 3$ region at a $\mathrm{RH}>63.6 \%$.

Figure $8 \mathrm{~b}$ shows the phase diagram with adipic acid $\left(\mathrm{ORG}_{1}\right)$ and glutaraldehyde $\left(\mathrm{ORG}_{2}\right)$ with the or- ganic/inorganic mixing ratio $\alpha=0.2$ and the organic fractions $f_{\mathrm{ORG}_{1}}=0.15$ and $f_{\mathrm{ORG}_{2}}=0.85$. The model predicts a twophase region (L2) in between two L1 regions. Most of the one-solid and all of the two-solids regions are covered by $\mathrm{L} 1$; the system consists of a single liquid (water + organics) phase in equilibrium, either with one solid (A, B, or $\mathrm{C}$ ) or two-solids $(\mathrm{A}+\mathrm{B}$, or $\mathrm{B}+\mathrm{C})$. $\mathrm{L} 1$ covers part of the liquid region, and the system is in a single-phase equilibrium. L2 covers the rest of the liquid region and parts of the one-solid region. There is no L3 region in this system. A slight decrease of the "deliquescence" RHs for A, B and C can be observed. The "deliquescence" RHs shown in Fig. 8b for A, $\mathrm{B}$ and $\mathrm{C}$ are $\sim 77 \%, \sim 66 \%$ and $\sim 34 \%$, while the original values in Fig. $7 \mathrm{a}$ are $\sim 80 \%, 68.57 \%$ and $36.65 \%$. Similarly for Fig. 8b, as represented by the dashed magenta curve and the second row of pie charts (labeled by (2)) in Fig. 10a, the system at $X=0.6$ starts at $\mathrm{RH}=0$ in a $\mathrm{L} 1$ region, where there is a single liquid phase mixed of organics and water with some dissolved ions of $\mathrm{B}$ and $\mathrm{C}$ in equilibrium with the solids $\mathrm{B}$ and $\mathrm{C}$. At $\mathrm{RH}=33.5 \%$ (a decrease of 3.1 compared to the baseline value of $36.6 \%$ in $(0)$ ), solid $C$ fully dissolves and the relative water content in the system reaches 0.34 , then the system consists of a single liquid (water + organics + dissolved ions of $\mathrm{B}$ and $\mathrm{C}$ ) phase in equilibrium with solid B. At $\mathrm{RH}=54.3 \%$, the system crosses the phase boundary between $\mathrm{L} 1$ and L2 (indicated by a dashed line with the relative water content being $8.35 \mathrm{e}-01$ ), then the system consists of two mixed organic + water phases with some dissolved ions $\mathrm{B}$ and $\mathrm{C}$ in equilibrium with solid B. As RH increases 
(a)

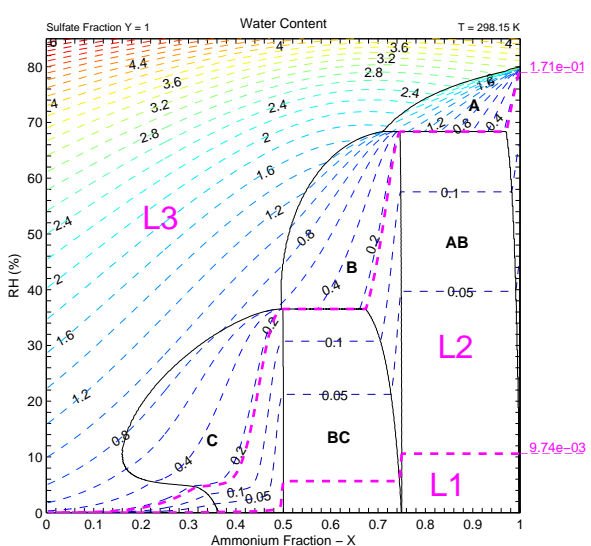

(c)

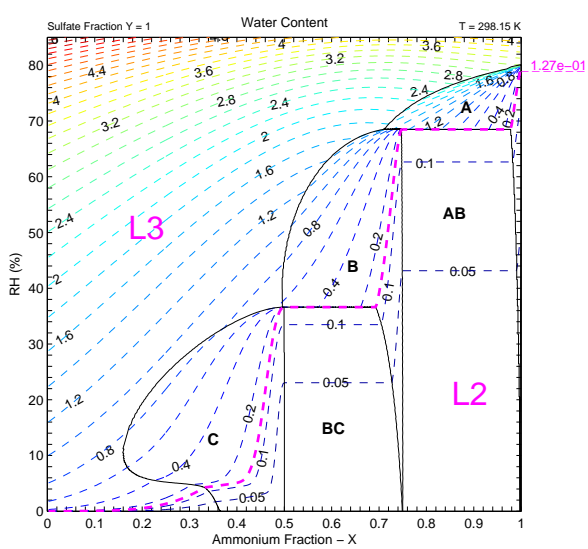

(b)

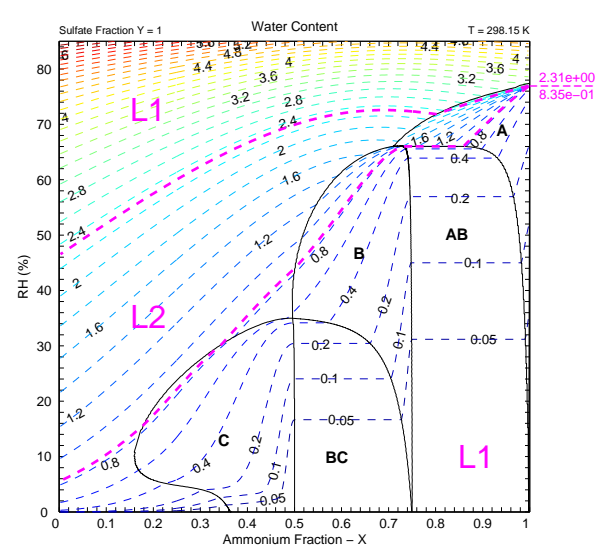

(d)

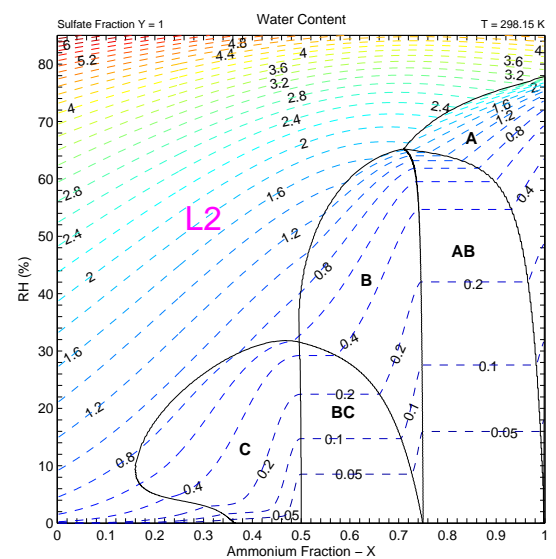

Fig. 8. Construction of the phase diagram for the system $\left(\mathrm{NH}_{4}\right)_{2} \mathrm{SO}_{4} / \mathrm{H}_{2} \mathrm{SO}_{4} / \mathrm{NH}_{4} \mathrm{NO}_{3} / \mathrm{HNO}_{3} / \mathrm{H}_{2} \mathrm{O}$ with the sulfate fraction $Y=1$ at $298.15 \mathrm{~K}$ when the system also includes two organic species: (a) 1-hexacosanol $\left(\mathrm{ORG}_{1}\right)$ and pinic acid $\left(\mathrm{ORG}_{2}\right)$ with $\alpha=0.2, f_{\mathrm{ORG}_{1}}=0.5$ and $f_{\mathrm{ORG}_{2}}=0.5$; (b) adipic acid $\left(\mathrm{ORG}_{1}\right)$ and glutaraldehyde $\left(\mathrm{ORG}_{2}\right)$ with $\alpha=0.2, f_{\mathrm{ORG}_{1}}=0.15$ and $f_{\mathrm{ORG}_{2}}=0.85$; (c) pinonic acid $\left(\mathrm{ORG}_{1}\right)$ and nonacosane $\left(\mathrm{ORG}_{2}\right)$ with $\alpha=0.2, f_{\mathrm{ORG}_{1}}=0.5$ and $f_{\mathrm{ORG}_{2}}=0.5$; (d) 2-hydroxy-glutaric acid $\left(\mathrm{ORG}_{1}\right)$ and palmitic acid $\left(\mathrm{ORG}_{2}\right)$ with $\alpha=0.2, f_{\mathrm{ORG}_{1}}=0.5$ and $f_{\mathrm{ORG}_{2}}=0.5$.

to $61.4 \%$ (a decrease of 2.4 compared to the baseline value of $63.8 \%$ in (0)), B dissolves and the system is in a two liquid phase equilibrium. No solid salt is present in system at a $\mathrm{RH}>61.4 \%$. At RH $=72.6 \%$, the system crosses the phase boundary between L 2 and L1 (indicated by a dashed line with the relative water content being 2.31), then the system is in a single-phase (aqueous phase) equilibrium.

Figure $8 \mathrm{c}$ presents the phase diagram with pinonic acid $\left(\mathrm{ORG}_{1}\right)$ and nonacosane $\left(\mathrm{ORG}_{2}\right)$ with the organic/inorganic mixing ratio $\alpha=0.2$ and the organic fractions $f_{\mathrm{ORG}_{1}}=0.5$ and $f_{\mathrm{ORG}_{2}}=0.5$. The phase diagram for this system is similar to that of 1-hexacosanol and pinic acid (Fig. 8a). L3 covers fully the liquid region and most of the one-solid regions. L2 covers fully the two-solids region; however, there is no L1 region predicted in this system.

Similarly for Fig. 8c, as represented by the dashed blue curve and the third row of pie charts (labeled by (3)) in
Fig. 10a, the system at $X=0.6$ starts at $\mathrm{RH}=0$ in a L2 region, where there are two mixed organic + water phases with some dissolved ions $\mathrm{B}$ and $\mathrm{C}$, and two solid phases $\mathrm{B}$ and $\mathrm{C}$ that are in equilibrium with the two liquid phases. When the $\mathrm{RH}$ reaches $36.6 \%$ (a decrease of 0.04 compared to the baseline value in (0)), solid $\mathrm{C}$ fully dissolves and the relative water content in the system promptly takes the value of 0.34 , then the system crosses the phase boundary between L2 and L3 (indicated by a dashed line with the relative water content being $1.27 \mathrm{e}-01)$. Within the L3 region, the system consists of two organic phases (each containing some amount of water and dissolved ions B and C) and an aqueous phase (with some amount of organics and dissolved ions $\mathrm{B}$ and $\mathrm{C}$ ), which are all in equilibrium with solid B. As RH increases to $63.7 \%$ (a decrease of 0.1 compared to the baseline value of $63.8 \%$ in (0)), B dissolves and the system is in a three liquid phase equilibrium (two organic phases with 
(a)

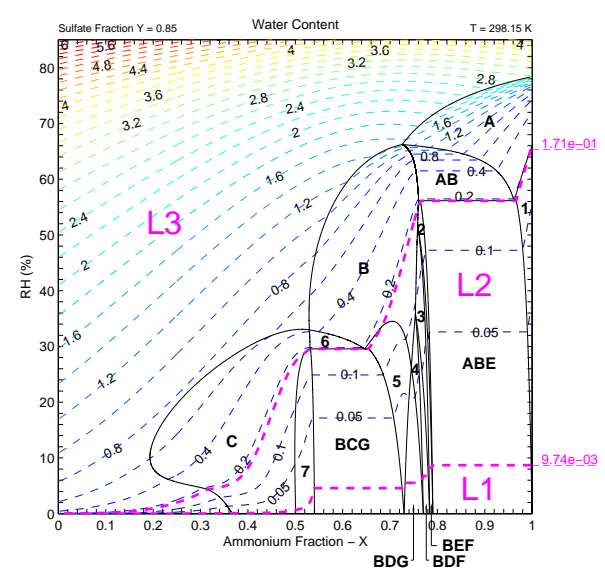

(c)

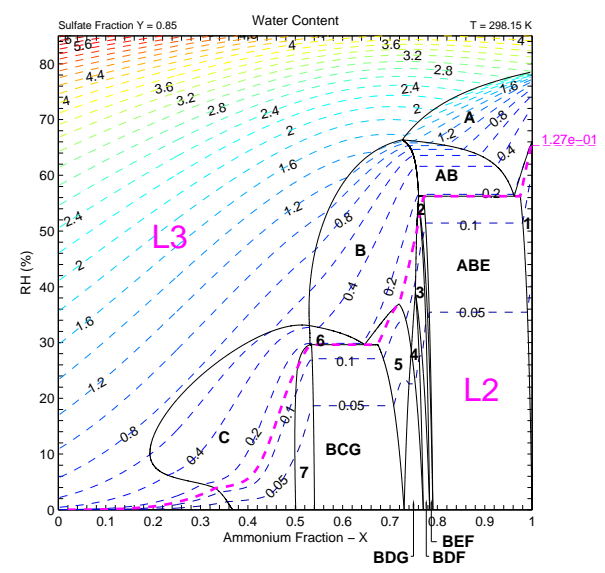

(b)

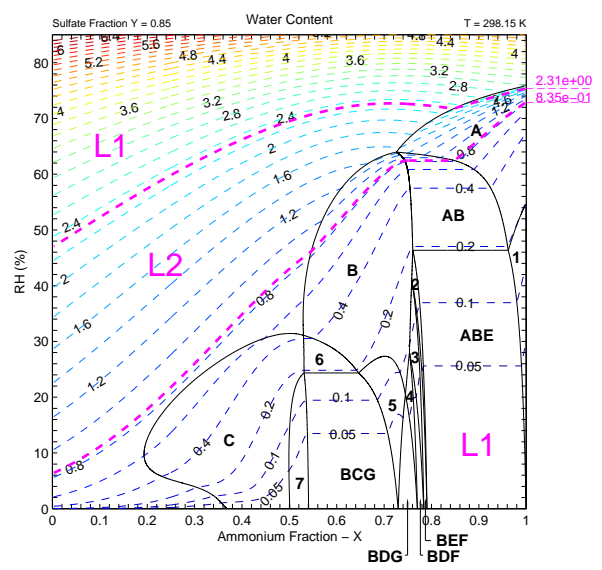

(d)

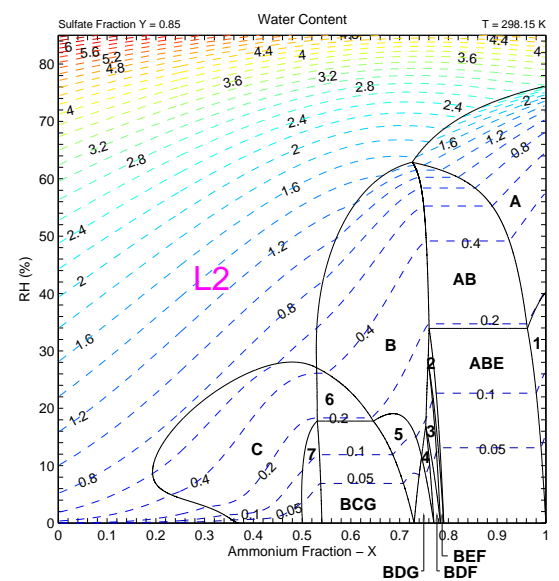

Fig. 9. Construction of the phase diagram for the system $\left(\mathrm{NH}_{4}\right)_{2} \mathrm{SO}_{4} / \mathrm{H}_{2} \mathrm{SO}_{4} / \mathrm{NH}_{4} \mathrm{NO}_{3} / \mathrm{HNO}_{3} / \mathrm{H}_{2} \mathrm{O}$ with the sulfate fraction $Y=0.85$ at $298.15 \mathrm{~K}$ when the system also includes two organic species: (a) 1-hexacosanol $\left(\mathrm{ORG}_{1}\right)$ and pinic acid $\left(\mathrm{ORG}_{2}\right)$ with $\alpha=0.2, f_{\mathrm{ORG}_{1}}=0.5$ and $f_{\mathrm{ORG}_{2}}=0.5$; (b) adipic acid $\left(\mathrm{ORG}_{1}\right)$ and glutaraldehyde $\left(\mathrm{ORG}_{2}\right)$ with $\alpha=0.2, f_{\mathrm{ORG}_{1}}=0.15$ and $f_{\mathrm{ORG}_{2}}=0.85$; (c) pinonic acid $\left.(\mathrm{ORG})_{1}\right)$ and nonacosane $\left(\mathrm{ORG}_{2}\right)$ with $\alpha=0.2, f_{\mathrm{ORG}_{1}}=0.5$ and $f_{\mathrm{ORG}_{2}}=0.5$; (d) 2-hydroxy-glutaric acid $\left(\mathrm{ORG}_{1}\right)$ and palmitic acid $\left(\mathrm{ORG}_{2}\right)$ with $\alpha=0.2, f_{\mathrm{ORG}_{1}}=0.5$ and $f_{\mathrm{ORG}_{2}}=0.5$.

some amount of water and dissolved ions and an aqueous phase with some amount of organics and dissolved ions). No solid salt is present in system within the L3 region at a $\mathrm{RH}>63.8 \%$. Figure $8 \mathrm{~d}$ shows the phase diagram with 2-hydroxy-glutaric acid $\left(\mathrm{ORG}_{1}\right)$ and palmitic acid $\left(\mathrm{ORG}_{2}\right)$ with the organic/inorganic mixing ratio $\alpha=0.2$ and the organic fractions $f_{\mathrm{ORG}_{1}}=0.5$ and $f_{\mathrm{ORG}_{2}}=0.5$. The entire phase diagram is labeled as a L2 region. A change in the "deliquescence" RHs of A, B and C can also be observed. The approximate values shown in Fig. 8d are $78 \%$ for A, $66 \%$ for B, and $32 \%$ for $\mathrm{C}$, whereas the original values in Fig. $7 \mathrm{a}$ are $80 \%$, $68.57 \%$, and $36.65 \%$. Similarly for Fig. 8d, as represented by the dashed cyan curve and the fourth row of pie charts (labeled by (4)) in Fig. 10a, the system at $X=0.6$ starts at RH $=0$ in the $\mathrm{L} 2$ region, where there are two mixed organic + water phases with some dissolved ions $\mathrm{B}$ and $\mathrm{C}$ in equilib- rium with the solids $\mathrm{B}$ and $\mathrm{C}$. At $\mathrm{RH}=27.8 \%$ (a decrease of 8.8 compared to the baseline value of $36.6 \%$ in $(0)$ ), solid $\mathrm{C}$ fully dissolves and the relative water content in the system reaches 0.34 , then the system consists of two liquid (water + organics + dissolved ions of $\mathrm{B}$ and $\mathrm{C}$ ) phases in equilibrium with solid B. As RH increases to $60.2 \%$ (a decrease of 3.6 compared to the baseline value of $63.8 \%$ in (0)), B dissolves and the system is in a two liquid phase equilibrium. No solid salt is present in system at a $\mathrm{RH}>60.2 \%$.

The phase diagrams of $\left(\mathrm{NH}_{4}\right)_{2} \mathrm{SO}_{4} / \mathrm{H}_{2} \mathrm{SO}_{4} / \mathrm{NH}_{4} \mathrm{NO}_{3} /$ $\mathrm{HNO}_{3} / \mathrm{H}_{2} \mathrm{O}$ for the same four $\mathrm{ORG}_{1} / \mathrm{ORG}_{2}$ combinations are given in Figs. 9a-d, at a fixed sulfate fraction $(Y)$ of 0.85 . Similar to the panels in Fig. 8, the horizontal boundaries corresponding to the mutual deliquescence RHs for the fully crystalline solid phases in Fig. 7b are now curved in Fig. 9. In the L3 regions of Fig. 9a and c, the addition of organic 
(a)

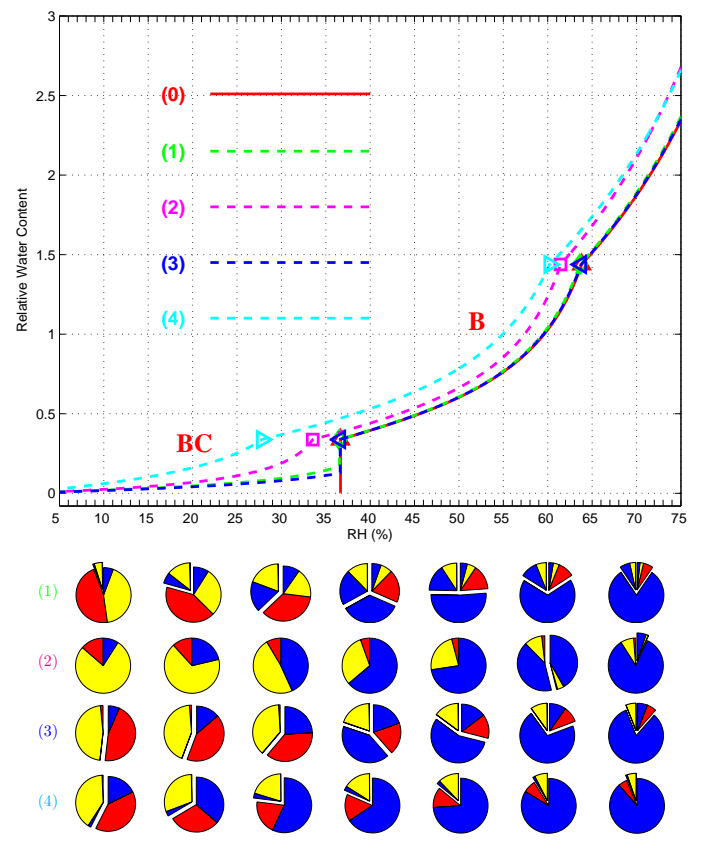

(b)
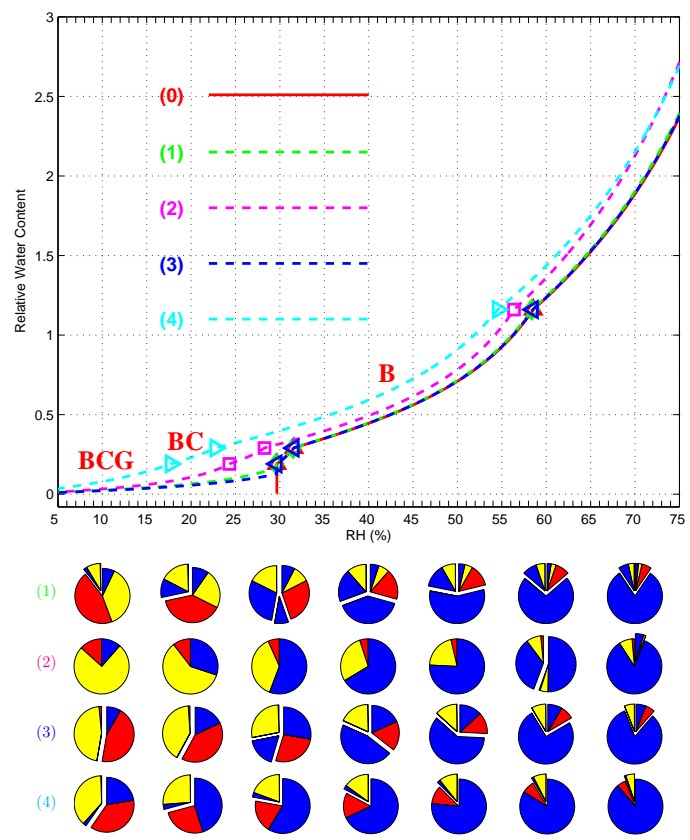

Fig. 10. Deliquescence curves for the system $\left(\mathrm{NH}_{4}\right)_{2} \mathrm{SO}_{4} / \mathrm{H}_{2} \mathrm{SO}_{4} / \mathrm{NH}_{4} \mathrm{NO}_{3} / \mathrm{HNO}_{3} / \mathrm{H}_{2} \mathrm{O}$ with the ammonium fraction $X=0.6$ and the sulfate fraction: (a) $Y=1$, (b) $Y=0.85$, at $298.15 \mathrm{~K}$. Relative water content (defined as the ratio $\frac{b_{\mathrm{H}_{2} \mathrm{O}}}{\sum_{i=1}^{n_{i}} b_{\mathrm{INORG}_{i}}}$ ) with changing relative humidity when (0) (solid red curve) the system is pure inorganic, or the system also includes two organic species with organic/inorganic mixing ratio $\alpha=0.2$ : (1) (dashed green curve) 1-hexacosanol $\left(\mathrm{ORG}_{1}\right)$ and pinic acid $\left(\mathrm{ORG}_{2}\right)$ with $f_{\mathrm{ORG}_{1}}=0.5$ and $f_{\mathrm{ORG}_{2}}=0.5$; (2) (dashed magenta curve) adipic acid $\left(\mathrm{ORG}_{1}\right)$ and glutaraldehyde $\left(\mathrm{ORG}_{2}\right)$ with $f_{\mathrm{ORG}_{1}}=0.15$ and $f_{\mathrm{ORG}_{2}}=0.85$; (3) (dashed blue curve) pinonic acid $\left.(\mathrm{ORG})_{1}\right)$ and nonacosane $\left(\mathrm{ORG}_{2}\right)$ with $f_{\mathrm{ORG}_{1}}=0.5$ and $f_{\mathrm{ORG}_{2}}=0.5$; (4) (dashed cyan curve) 2-hydroxy-glutaric acid $\left(\mathrm{ORG}_{1}\right)$ and palmitic acid $\left(\mathrm{ORG}_{2}\right)$ with $f_{\mathrm{ORG}_{1}}=0.5$ and $f_{\mathrm{ORG}_{2}}=0.5$. These curves represent the relative water content on the vertical cuts at $X=0.6$ in Figs. 7-9. The pie charts below each panel show, at the RH-values of $10,20,30,40,50,60,70$, the contents of two organics $\left(\mathrm{ORG}_{1}\right.$ and $\left.\mathrm{ORG}_{2}\right)$ and water $\left(\mathrm{H}_{2} \mathrm{O}\right)$ in each liquid phase, represented counterclockwise by three adjacent sectors that are colored in red, yellow and blue, respectively. The size of a sector is proportional to the corresponding quantity.

species has a negligible effect on the hygroscopic properties of the inorganic electrolytes. In general, the phase diagrams follow a structure similar to those shown in Fig. 8. Comparing Figs. 8 and 9, it can be seen that the same number of L1, L2, and L3 regions are predicted, covering similar regions of the phase diagram. Figure 9a shows the system including 1-hexacosanol $\left(\mathrm{ORG}_{1}\right)$ and pinic acid $\left(\mathrm{ORG}_{2}\right)$. The L3 region fully covers the liquid region and the one-solid regions, with the addition of the two-solid region $\mathrm{AB}$ and region $6(\mathrm{~B}+\mathrm{C})$. The $\mathrm{L} 2$ region covers most of the two-solids and three solids regions, and L1 covers small parts of the two-solids and three-solids regions. In Fig. 9b, a similar distribution of the two L1 and L2 regions is observed, as compared to Fig. 8b. However, the mutual "deliquescence" RH of $\mathrm{ABE}$ and $\mathrm{BCG}$ in Fig. 9b is significantly lower than that in Fig. 7b. The "deliquescence" RHs for ABE and BCG in Fig. $9 \mathrm{~b}$ are $<\sim 46 \%$ and $<\sim 24 \%$ (compared to the original values of $56.31 \%$ and $29.65 \%$ in Fig. 7b). In Fig. 9c, L3 covers the entire liquid region, most of the one-solid region
$(\mathrm{A}, \mathrm{B}$, and $\mathrm{C})$, and the two-solid region $\mathrm{AB}$ and $6(\mathrm{~B}+\mathrm{C})$. $\mathrm{L} 2$ covers the rest of the two-solid regions and all the threesolids region. In Fig. 9d, the L2 region also covers the entire phase diagram, as in Fig. 8d. However, significant a decrease of the mutual "deliquescence" RHs can be observed for $\mathrm{ABE}, \mathrm{BEF}, \mathrm{BDF}, \mathrm{BDG}, \mathrm{BCG}$. For instance, the "deliquescence" $\mathrm{RH}$ for $\mathrm{ABE}$ is $<\sim 34 \%$ (in Fig. 9d), while the original DRH for ABE in Fig. 7b is $56.31 \%$. The "deliquescence" $\mathrm{RH}$ for BCG is shown to be $<\sim 18 \%$, but the original value in Fig. 7 b is $29.65 \%$ in Fig. 7b). Similarly for Fig. 9, Fig. 10b shows deliquescence curves that represent the relative water content on the vertical cuts at $X=0.6$ in Fig. 9; they are: (1) the dashed green curve and the first row of pie charts for Fig. 9a with multistage deliquescence RHs (\%) for BCG, BC and B being 29.6, 31.5 and 58.4, respectively (a decrease of $0.1,0.1$ and 0.1 , respectively, compared to the baseline values of 29.7, 31.6 and 58.5 in (0)), (2) the dashed magenta curve and the second row of pie charts for Fig. $9 \mathrm{~b}$ with multistage deliquescence RHs for BCG, BC and B being 
(a)
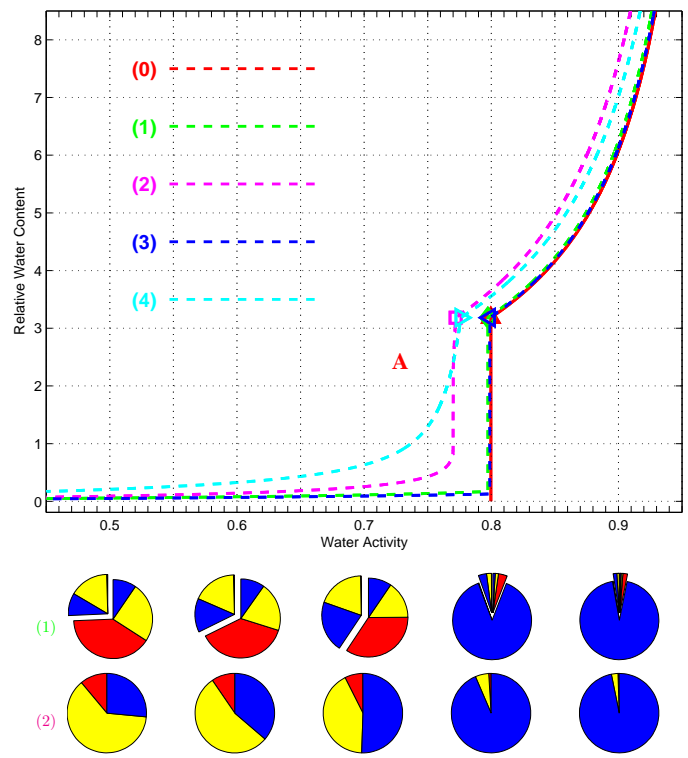

(3)
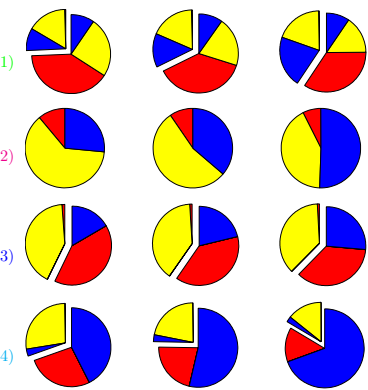

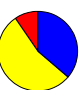
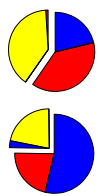
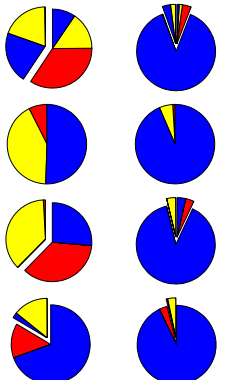

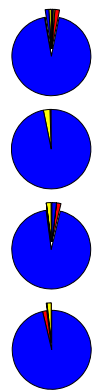

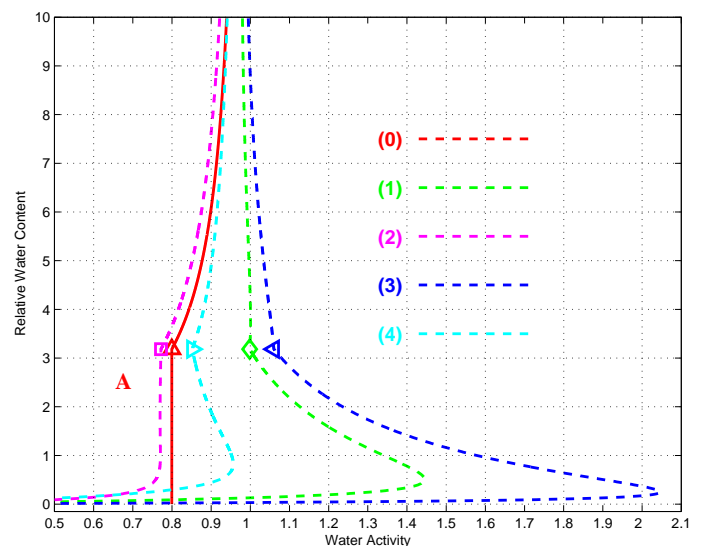

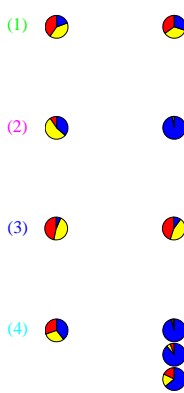

(b)

Fig. 11. Deliquescence curves for the system $\left(\mathrm{NH}_{4}\right)_{2} \mathrm{SO}_{4}(\mathrm{AS}) / \mathrm{H}_{2} \mathrm{O}$ at $298.15 \mathrm{~K}$, constructed by: (a) calculating the liquid phase equilibria occurring in the system, (b) assuming only one liquid phase occurring in the system.

Relative water content vs. water activity $\left(a_{w}\right)$ when $(0)$ (solid red curve) the system is pure inorganic, or the system also includes two organic species with organic/inorganic mixing ratio $\alpha=0.2$ : (1) (dashed green curve) 1-hexacosanol $\left(\mathrm{ORG}_{1}\right)$ and pinic acid $\left(\mathrm{ORG}_{2}\right)$ with $f_{\mathrm{ORG}_{1}}=0.5$ and $f_{\mathrm{ORG}_{2}}=0.5$; (2) (dashed magenta curve) adipic acid $\left(\mathrm{ORG}_{1}\right)$ and glutaraldehyde $\left(\mathrm{ORG}_{2}\right)$ with $f_{\mathrm{ORG}_{1}}=0.15$ and $f_{\mathrm{ORG}_{2}}=0.85$; $(3)$ (dashed blue curve) pinonic acid $\left(\mathrm{ORG}_{1}\right)$ and nonacosane $\left(\mathrm{ORG}_{2}\right)$ with $f_{\mathrm{ORG}_{1}}=0.5$ and $f_{\mathrm{ORG}_{2}}=0.5$; (4) (dashed cyan curve) 2-hydroxyglutaric acid $\left(\mathrm{ORG}_{1}\right)$ and palmitic acid $\left(\mathrm{ORG}_{2}\right)$ with $f_{\mathrm{ORG}_{1}}=0.5$ and $f_{\mathrm{ORG}_{2}}=0.5$. The pie charts below each panel show, at various water activities: $0.5,0.6,0.7,0.8,0.9$ in $(\mathrm{a})$, or $0.6,0.9,1.2,1.5,1.8$ in (b), the contents of two organics $\left(\mathrm{ORG}_{1}\right.$ and $\left.\mathrm{ORG} 2\right)$ and water $\left(\mathrm{H}_{2} \mathrm{O}\right)$ in each liquid phase, represented counterclockwise by three adjacent sectors that are colored in red, yellow and blue, respectively. The size of a sector is proportional to the corresponding quantity. A stack of pie charts in (b) indicates that there are multiple configurations of the liquid phase at a given water activity.

24.3, 28.3 and 56.4, respectively (a decrease of 5.4, 3.3, and 2.1 , respectively, compared to the baseline values), (3) the dashed blue curve and the third row of pie charts for Fig. 9c with multistage deliquescence RHs for BCG, BC and B being 29.6, 31.5 and 58.5, respectively (a decrease of $0.1,0.1$, and 0.04 , respectively, compared to the baseline values), and (4) the dashed cyan curve and the fourth row of pie charts for Fig. 9d with multistage deliquescence RHs for BCG, BC and B being 17.7, 22.7 and 54.5, respectively (a decrease of 12., 8.9, and 4.0, respectively, compared to the baseline values).

The pie charts in Figs. 10a and 10b show the liquid phases equilibrium partitioning of water and two organics in system at the RH-values of $10,20,30,40,50,60$, and 70 along the four deliquescence curves presented therein. The contents of two organics $\left(\mathrm{ORG}_{1}\right.$ and $\left.\mathrm{ORG}_{2}\right)$ and water $\left(\mathrm{H}_{2} \mathrm{O}\right)$ in each liquid phase are represented counterclockwise by three adjacent sectors that are colored in red, yellow and blue, respectively. The size of a sector is proportional to the corresponding quantity, whose value for case (1) in Fig. 10a, for example, is given by: at RH $=10 \%$, $\left(y_{1}, y_{2}\right)=(5.8 \%, 94.2 \%)$

with $\boldsymbol{x}_{1}^{o}=(.042, .815, .143)$ and $\boldsymbol{x}_{2}^{o}=(.493, .446, .061)$; at $\mathrm{RH}=20 \%,\left(y_{1}, y_{2}\right)=(20.7 \%, 79.3 \%)$ with $\boldsymbol{x}_{1}^{o}=(.023, .675, .302)$ and $\boldsymbol{x}_{2}^{o}=(.528, .358, .114)$; at $\mathrm{RH}=30 \%,\left(y_{1}, y_{2}\right)=(37.1 \%, 62.9 \%)$ with $\boldsymbol{x}_{1}^{o}=(.008, .511, .481)$ and $\boldsymbol{x}_{2}^{o}=(.571, .275, .154)$; at $\mathrm{RH}$ $=40 \%,\left(y_{1}, y_{2}, y_{3}\right)=(33.0 \%, 35.4 \%, 31.6 \%)$ with $\boldsymbol{x}_{1}^{o}=(.002, .372, .626), \boldsymbol{x}_{2}^{o}=\left(10^{-12}, .003, .997\right)$ and $\boldsymbol{x}_{3}^{o}=(.609, .219, .172)$; at $\mathrm{RH}=50 \%,\left(y_{1}, y_{2}, y_{3}\right)$ $=(24.7 \%, 51.5 \%, 23.8 \%) \quad$ with $\quad x_{1}^{o}=(.002, .372, .626)$, $\boldsymbol{x}_{2}^{o}=\left(10^{-12}, .003, .997\right)$ and $\boldsymbol{x}_{3}^{o}=(.609, .219, .172)$; at $\mathrm{RH}=60 \%,\left(y_{1}, y_{2}, y_{3}\right)=(16.1 \%, 68.1 \%, 15.8 \%)$ 
(a)

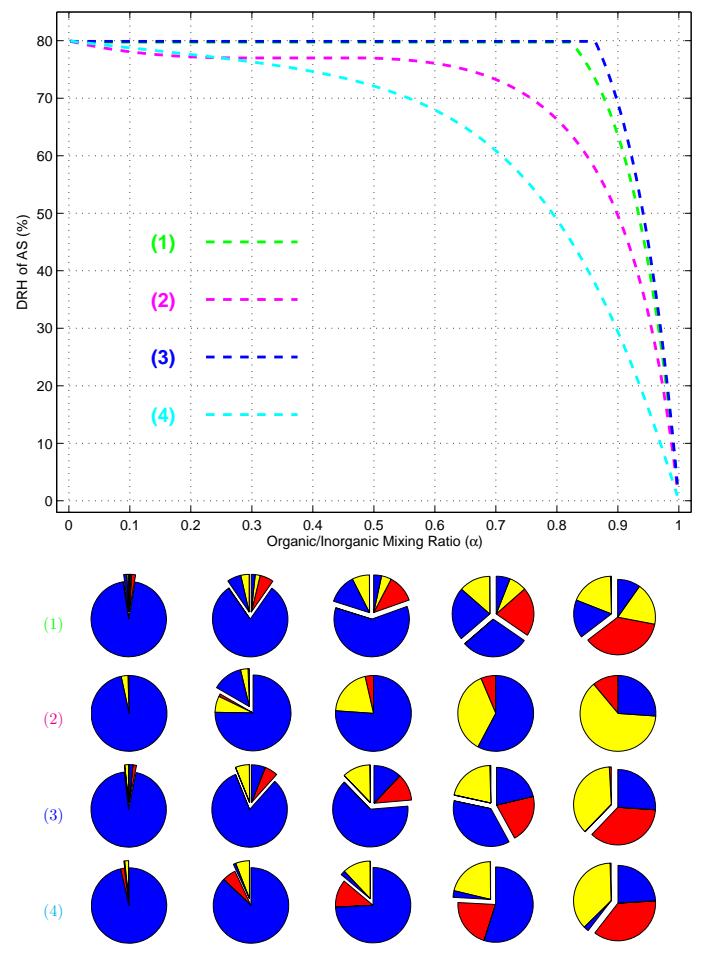

(b)
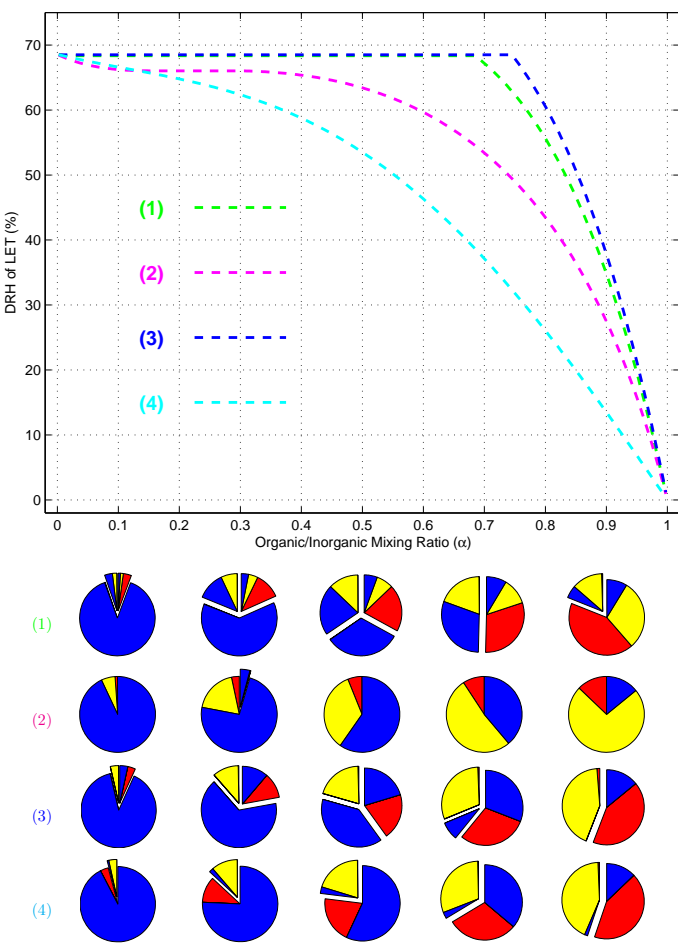

Fig. 12. Deliquescence relative humidity for the system: (a) $\left(\mathrm{NH}_{4}\right)_{2} \mathrm{SO}_{4}(\mathrm{AS}) / \mathrm{H}_{2} \mathrm{O}$, (b) $\left(\mathrm{NH}_{4}\right)_{3} \mathrm{H}(\mathrm{SO})_{2}(\mathrm{LET}) / \mathrm{H}_{2} \mathrm{O}$, at $298.15 \mathrm{~K}$ with changing organic/inorganic mixing ratio $\alpha$ (defined in Eq. 12) when the system also includes two organic species: (1) (dashed green curve) 1-hexacosanol $\left(\mathrm{ORG}_{1}\right)$ and pinic acid $\left(\mathrm{ORG}_{2}\right)$ with $f_{\mathrm{ORG}_{1}}=0.5$ and $f_{\mathrm{ORG}_{2}}=0.5$; (2) (dashed magenta curve) adipic acid $\left(\mathrm{ORG}_{1}\right)$ and glutaraldehyde $\left(\mathrm{ORG}_{2}\right)$ with $f_{\mathrm{ORG}_{1}}=0.15$ and $f_{\mathrm{ORG}_{2}}=0.85$; (3) (dashed blue curve) pinonic acid $\left(\mathrm{ORG}_{1}\right)$ and nonacosane $\left(\mathrm{ORG}_{2}\right)$ with $f_{\mathrm{ORG}_{1}}=0.5$ and $f_{\mathrm{ORG}_{2}}=0.5$; (4) (dashed cyan curve) 2-hydroxy-glutaric acid $\left(\mathrm{ORG}_{1}\right)$ and palmitic acid $\left(\mathrm{ORG}_{2}\right)$ with $f_{\mathrm{ORG}_{1}}=0.5$ and $f_{\mathrm{ORG}_{2}}=0.5$. The pie charts below each panel show, at various organic/inorganic mixing ratios $(\alpha): 0.1,0.3,0.5,0.7,0.9$, the contents of two organics $\left(\mathrm{ORG}_{1}\right.$ and $\left.\mathrm{ORG}_{2}\right)$ and water $\left(\mathrm{H}_{2} \mathrm{O}\right)$ in each liquid phase, represented counterclockwise by three adjacent sectors that are colored in red, yellow and blue, respectively. The size of a sector is proportional to the corresponding quantity.

with $x_{1}^{o}=(.002, .372, .626), \quad x_{2}^{o}=\left(10^{-12}, .003, .997\right)$ and $\boldsymbol{x}_{3}^{o}=(.609, .219, .172) ;$ at $\mathrm{RH}=70 \%$,

$\left(y_{1}, y_{2}, y_{3}\right)=(9.4 \%, 81.1 \%, 9.5 \%)$ with

$\boldsymbol{x}_{1}^{o}=(.002, .372, .626), \boldsymbol{x}_{2}^{o}=\left(10^{-12}, .003, .997\right)$ and

$\boldsymbol{x}_{3}^{o}=(.609, .219, .172)$.

Here, $y_{\alpha}$ denotes the total number (fraction) of moles in phase $\alpha$ and $\boldsymbol{x}_{\alpha}^{o}=\left(x_{\mathrm{ORG}_{1}}^{o_{\alpha}}, x_{\mathrm{ORG}_{2}}^{o_{\alpha}}, x_{\mathrm{H}_{2} \mathrm{O}}^{o_{\alpha}}\right)$ denotes the (partial) mole fraction vector (of the two organics and water) for phase $\alpha$ with $\alpha=1,2$, or 3 . Thus, the contents of two organics $\left(\mathrm{ORG}_{1}\right.$ and $\left.\mathrm{ORG}_{2}\right)$ and water $\left(\mathrm{H}_{2} \mathrm{O}\right)$ in phase $\alpha$, for $\alpha=1$, 2 , or 3 , are given by $y_{\alpha} x_{\mathrm{ORG}_{1}}^{o_{\alpha}}, y_{\alpha} x_{\mathrm{ORG}_{2}}^{o_{\alpha}}$ and $y_{\alpha} x_{\mathrm{H}_{2} \mathrm{O}}^{o_{\alpha}}$, respectively. Note that at $\mathrm{RH}>36.5 \%$ for case (1) in Fig. 10a, the mixture is partitioned into three equilibrium liquid-phases: two organic phases of compositions $\boldsymbol{x}_{1}^{o}$ and $\boldsymbol{x}_{3}^{o}$ and an aqueous phase of composition $\boldsymbol{x}_{2}^{o}$, thus the system has a maximum number of liquid phases permissible by the Gibbs phase rule; as RH increases, the compositions of the three liquid-phases $\boldsymbol{x}_{1}^{o}, \boldsymbol{x}_{2}^{o}$ and $\boldsymbol{x}_{3}^{o}$ stay the same, the total numbers of moles in the two organic phases $y_{1}$ and $y_{3}$ decrease, whereas the total number of moles in the aqueous phase $y_{2}$ increases. It should be noted that sectors of small quantity are not visible in the present scale.

Figure 11 shows deliquescence curves for the system $\left(\mathrm{NH}_{4}\right)_{2} \mathrm{SO}_{4}(\mathrm{AS}) / \mathrm{H}_{2} \mathrm{O}$ at $298.15 \mathrm{~K}$, when (0) (solid red curve) the system is pure inorganic, or the system also includes two organic species with organic/inorganic mixing ratio $\alpha=0.2$ : (1) (dashed green curve) 1-hexacosanol $\left(\mathrm{ORG}_{1}\right)$ and pinic acid $\left(\mathrm{ORG}_{2}\right)$ with $f_{\mathrm{ORG}_{1}}=0.5$ and $f_{\mathrm{ORG}_{2}}=0.5$; (2) (dashed magenta curve) adipic acid $\left(\mathrm{ORG}_{1}\right)$ and glutaraldehyde $\left(\mathrm{ORG}_{2}\right)$ with $f_{\mathrm{ORG}_{1}}=0.15$ and $f_{\mathrm{ORG}_{2}}=0.85$; (3) (dashed blue curve) pinonic acid $\left(\mathrm{ORG}_{1}\right)$ and nonacosane $\left(\mathrm{ORG}_{2}\right)$ with $f_{\mathrm{ORG}_{1}}=0.5$ and $f_{\mathrm{ORG}_{2}}=0.5$; (4) (dashed cyan curve) 2-hydroxy-glutaric acid $\left(\mathrm{ORG}_{1}\right)$ and palmitic acid $\left(\mathrm{ORG}_{2}\right)$ with $f_{\mathrm{ORG}_{1}}=0.5$ and $f_{\mathrm{ORG}_{2}}=0.5$. When mixed with the organics $\left(\mathrm{ORG}_{1}\right.$ and $\left.\mathrm{ORG}_{2}\right)$, the deliquescence curves are constructed by: (a) calculating the liquid phase equilibria occurring in the system, (b) assuming only one liquid phase occurring in the system. The curves in (a) represent the relative water content on the vertical cuts at $X=1$ in Figs. 7a and 8. The pie charts below each panel show, at various water activities: $0.5,0.6,0.7,0.8,0.9$ in (a), or $0.6,0.9,1.2,1.5,1.8$ in (b), the contents of two organics $\left(\mathrm{ORG}_{1}\right.$ and $\left.\mathrm{ORG}_{2}\right)$ and 
water $\left(\mathrm{H}_{2} \mathrm{O}\right)$ in each liquid phase, represented counterclockwise by three adjacent sectors that are colored in red, yellow and blue, respectively. The size of a sector is proportional to the corresponding quantity. The deliquescence curve and pie charts for case (2) in Fig. 11a are identical to the deliquescence curve and pie charts for case (2) in Fig. 11b, as the system for case (2) in (a) is in a single liquid (water + organics) phase equilibrium, which is the phase assumption used in (b).

However, for cases (1), (3) and (4) in (a), the phase pie charts and water uptake are quite different as compared to those in (b), as the system for cases (1), (3) and (4) in (a) is in multiple liquid phase equilibrium, whereas the system in (b) is assumed to involve only one liquid phase. Note that the curves (1), (3) and (4) and their corresponding pie charts in Fig. $11 \mathrm{~b}$ are not physical, as they contradict thermodynamic principles: the value of water activity needs to be less than or equal to 1 and needs to be a monotonic increasing function of the water content (a consequence of Gibbs tangent plane criterion). The violation is due to the erroneous assumption of only one liquid phase involved in the system for cases (1), (3) and (4), where the organic contribution to the activity of water $a_{w}^{(o)}$ can take a value greater than 1. Moreover, a stack of pie charts in Fig. 11b indicates that there are multiple configurations of the liquid phase at a given water activity. At water activity $a_{w}=0.9$, for example, the relative water content for case (1), (3), (4) in (a) is 6.23, 6.13, 7.02, respectively, compared to the values of $0.108,0.0275,4.89$ (or 1.90, or 0.443), respectively, for case (1), (3) or (4) in (b). Note that there is a stack of three pie charts at $a_{w}=0.9$ for case (4) in (b), representing three different configurations of the liquid phase with the relative water content being 4.89 , 1.90 , and 0.443 , respectively, all of them give $\mathrm{RH}=90 \%$, but none of them is physical.

Therefore, calculating liquid phase equilibrium is necessary for thermodynamically consistent prediction of inorganic deliquescence behavior in the presence of organic species that are "partially miscible" or "immiscible".

Figure 12 shows deliquescence relative humidity for the system: (a) $\left(\mathrm{NH}_{4}\right)_{2} \mathrm{SO}_{4}(\mathrm{AS}) / \mathrm{H}_{2} \mathrm{O}$, (b) $\left(\mathrm{NH}_{4}\right)_{3} \mathrm{H}\left(\mathrm{SO}_{4}\right)_{2}(\mathrm{LET}) / \mathrm{H}_{2} \mathrm{O}$, at $298.15 \mathrm{~K}$ with changing organic/inorganic mixing ratio $\alpha$ (defined in Eq. 12) when the system also includes the two organic species $\left(\mathrm{ORG}_{1}\right.$ and $\left.\mathrm{ORG}_{2}\right)$. A decrease in DRH of AS and LET is observed and the magnitude of the change depends on both the type of organics present in the system and the corresponding organic/inorganic mixing ratio. This is to be expected based on the thermodynamics of mixed aerosols (Tang, 1976). The pie charts below each panel show, at various organic/inorganic mixing ratios $(\alpha)$ : $0.1,0.3,0.5$, $0.7,0.9$, the contents of two organics $\left(\mathrm{ORG}_{1}\right.$ and $\left.\mathrm{ORG}_{2}\right)$ and water $\left(\mathrm{H}_{2} \mathrm{O}\right)$ in each liquid phase, represented counterclockwise by three adjacent sectors that are colored in red, yellow and blue, respectively. The size of a sector is proportional to the corresponding quantity. As shown in Fig. 11, liquid phase equilibrium calculation is required here to quantify the effect of organics on the deliquescence relative humidity of inorganic salts.

\section{Effect of the version of UNIFAC on predicted liquid- liquid equilibria}

The challenge in modeling systems containing water, electrolytes, and organic compounds is twofold. First, there is no generally accepted theoretical model for such mixtures; second, there are insufficient data to constrain a model, as compared, say, to models of electrolyte-water solutions. The models that do exist work only over limited ranges of composition and concentration. The electrolyte-water model that is generally considered as the benchmark is the Aerosol Inorganic Model (AIM) (Clegg et al., 1998 a,b). A general, and widely-used, predictive thermodynamic model for organic liquid mixtures is UNIFAC (Fredenslund et al., 1977), which is based on a group contribution approach. Most thermodynamic models for organic/inorganic/water mixtures use, in some measure, both of these models. The CSB model used in the present work treats organic-water and ion-water interactions separately. Additional terms, which are proportional to ion and organic compound molalities, can be included to describe organic-ion interactions. The ion-water interaction is calculated using AIM, while the organic-water interaction is calculated employing UNIFAC. Interactions between electrolytes and organics are accounted for by additional terms derived from the Pitzer molality-based model. Experimental data are required to determine the mixture parameters; if mixture parameters are available, the Pitzer equations are well validated for solutions at low to moderate concentrations. For the systems studies here, mixture parameters are not available and are set to zero, as in the study of Clegg and Seinfeld (2006a). It is not possible at this point, owing largely to the lack of experimental data, to assess the effect of not including specific electrolyte-organic interactions. It is possible to assess the effect of the different versions of UNIFAC on the predicted liquid-liquid equilibria, and we do so here.

The interaction parameters listed in Table 2 contribute to the residual term of the UNIFAC equation (Fredenslund, et al. 1977) through the energy interaction term, $\Psi_{m n}$ :

$\Psi_{m n}=\exp \left(-A_{m n} / T\right)$

where $A_{m n}\left(\mathrm{~K}^{-1}\right)$ is the energy interaction parameter between groups $m$ and $n$. There are two interaction parameters for each pair of functional groups $m$ and $n, A_{m n}$ and $A_{n m}$, where $A_{m n} \neq A_{n m}$. Changes in the parameters from UNIFAC (Hansen et al., 1991) to UNIFAC-Peng (Peng et al., 2001) and UNIFAC to UNIFAC-LL (Magnussen et al., 1981) and their effects on the interaction terms are summarized in 
Table 5. Changes in the UNIFAC energy interaction parameters, $A_{m n}$ and $A_{n m}$, between UNIFAC/UNIFAC-Peng and UNIFAC/UNIFACLL, and their effect on the energy interaction terms, $\Psi_{m n}$ and $\Psi_{n m}$.

\begin{tabular}{|c|c|c|c|c|c|c|}
\hline & \multicolumn{3}{|c|}{ UNIFAC-Peng } & \multicolumn{3}{|c|}{ UNIFAC-LL } \\
\hline & $A_{m n} / A_{n m}$ & $\Psi_{m n} / \Psi_{n m}$ & overall & $A_{m n} / A_{n m}$ & $\Psi_{m n} / \Psi_{n m}$ & overall \\
\hline $\mathrm{OH} / \mathrm{H}_{2} \mathrm{O}$ & dec./dec. ${ }^{\mathrm{a}}$ & inc./inc. ${ }^{b}$ & increase & dec./inc. & inc. $(0.6) /$ dec. $(1.0)^{\mathrm{c}}$ & decrease \\
\hline $\mathrm{COOH} / \mathrm{H}_{2} \mathrm{O}$ & dec./dec. & inc./inc. & increase & inc./dec. & dec.(1.1)/inc.(3.7) & increase \\
\hline $\mathrm{OH} / \mathrm{COOH}$ & inc./inc. & dec./dec. & decrease & dec./inc. & inc.(0.9)/dec.(1.0) & decrease \\
\hline $\mathrm{CH}_{2} / \mathrm{H}_{2} \mathrm{O}$ & same & same & same & dec./inc. & inc. $(0.001) /$ dec. $(0.4)$ & decrease \\
\hline $\mathrm{CH}_{2} / \mathrm{OH}$ & same & same & same & dec./inc. & inc. $(0.9) /$ dec. $(0.3)$ & decrease \\
\hline $\mathrm{CH}_{2} / \mathrm{COOH}$ & same & same & same & dec./inc. & inc. $(0.5) /$ dec. $(0.3)$ & increase \\
\hline
\end{tabular}

a dec. $=$ decrease $=$ negative change

$\mathrm{b}$ inc. $=$ increase $=$ positive change

c number in brackets is the magnitude of the change

Table 5. Since the interaction term, $\Psi_{m n}$ or $\Psi_{n m}$, is the exponential of the negative of the interaction parameter $\mathrm{A}_{m n}$ or $\mathrm{A}_{n m}$, respectively, an increase/decrease in the interaction parameter, $A_{m n}$ or $A_{n m}$, leads to a decrease/increase in the interaction term, $\Psi_{m n}$ or $\Psi_{n m}$. The overall change in the interaction between groups $m$ and $n$ is approximately related to the sum of the changes of $\Psi_{m n}$ and $\Psi_{n m}$. For example, the overall change in the interaction between groups $\mathrm{OH}$ and $\mathrm{H}_{2} \mathrm{O}$ in UNIFAC-LL vs. UNIFAC is a decrease, due to the sum of the changes of $\Psi_{\mathrm{OH}, \mathrm{H}_{2} \mathrm{O}}$ (of value 0.6) and $\Psi_{\mathrm{H}_{2} \mathrm{O}, \mathrm{OH}}$ (of value -1.0 ) being -0.4 .

Figure 6 shows the liquid phase equilibrium predictions for the system water/1-hexacosanol(X5)/pinic acid(X7) using UNIFAC-Peng and UNIFAC-LL parameters. With all else equal, the changes between Figs. 6 and 2a can be roughly explained by the changes in the energy interaction parameters. The group-group interactions in the system include $\mathrm{CH}_{3}, \mathrm{CH}_{2}, \mathrm{OH}$ of 1-hexacosanol and $\mathrm{CH}_{3}, \mathrm{CH}_{2}$, $\mathrm{CH}, \mathrm{C}, \mathrm{COOH}$ of pinic acid (see Table 1).

\subsection{UNIFAC vs. UNIFAC-Peng}

In UNIFAC-Peng the $\mathrm{OH} / \mathrm{H}_{2} \mathrm{O}, \mathrm{COOH} / \mathrm{H}_{2} \mathrm{O}$ and $\mathrm{OH} / \mathrm{COOH}$ interaction parameters are modified by fitting the UNIFAC equation to experimental measurements of water-soluble dicarboxylic and multifunctional acids. Therefore, UNIFAC and UNIFAC-Peng parameters are identical except for the interactions between $\mathrm{OH} / \mathrm{H}_{2} \mathrm{O}, \mathrm{COOH} / \mathrm{H}_{2} \mathrm{O}$ and $\mathrm{OH} / \mathrm{COOH}$. According to Table 2, the interaction parameter $\left(A_{m n}\right)$ for $\mathrm{OH}-\mathrm{H}_{2} \mathrm{O}$ decreases from 353.3 (UNIFAC) to 265.97 (UNIFAC-Peng), leading to an increase in the interaction term $\Psi_{m n}$. At the same time, the $\mathrm{H}_{2} \mathrm{O}-\mathrm{OH}$ parameter changes from -229.1 (UNIFAC) to -467.4 (UNIFACPeng), causing an increase in the interaction term $\Psi_{n m}$. The overall effect is an increase in the $\mathrm{OH} / \mathrm{H}_{2} \mathrm{O}$ interaction. Similarly, the changes in the interaction parameters for $\mathrm{COOH} / \mathrm{H}_{2} \mathrm{O}$ from UNIFAC to UNIFAC-Peng result in a stronger interaction, and the changes in $\mathrm{OH} / \mathrm{COOH}$ lead to a weaker interaction (Table 5). We note that the interactions between $\mathrm{CH}_{2} / \mathrm{H}_{2} \mathrm{O}, \mathrm{CH}_{2} / \mathrm{OH}$ and $\mathrm{CH}_{2} / \mathrm{COOH}$ remain the same, thus do not contribute directly to the changes in phase structures predicted when replacing UNIFAC with UNIFAC-Peng. The changes between Figs. $6 \mathrm{a}$ and $2 \mathrm{a}$ in terms of phase structures predicted for the system water/1hexacosanol(X5)/pinic acid(X7) using UNIFAC-Peng vs. UNIFAC parameters can be readily analyzed by comparing the phase diagrams of their corresponding binary systems, namely water/X5, water/X7, and X5/X7. The change in phase structure for water/X5 can be attributed to the increasing interaction between $\mathrm{OH} / \mathrm{H}_{2} \mathrm{O}$, resulting in an increased miscibility of X5 from 0.1016 to 0.2754 when replacing UNIFAC by UNIFAC-Peng. The miscibility is the value of the water fraction of the organic phase that is in equilibrium with the aqueous phase, and is derived from the values listed in Table 2 . The increased miscibility of X5 when using UNIFAC-Peng leads to a reduced L2 (two-liquid) region that is bounded between the left edge of the triangular shaped L3 region and the $y$-axis where the mixtures separate along the tie-lines into two phases: an almost pure water phase and a mixed organic phase with the concentrations of 1-hexacosanol (mole fractions ranging from about 0.582 to 0.725 ) being lower when compared to the corresponding values by UNIFAC (mole fractions ranging from about 0.609 to 0.894 ). Similarly, the change in phase structure for water/X7 can be attributed to the increasing interaction between $\mathrm{COOH} / \mathrm{H}_{2} \mathrm{O}$, resulting in an increased miscibility of $\mathrm{X} 7$ from 0.6345 to 0.7924 when replacing UNIFAC by UNIFAC-Peng, thus leading in turn to a reduced L2 (two-liquid) region (not visible in the present scale) that is bounded between the left edge of the triangular shaped L3 region and the $x$-axis. The combined effect of the increased miscibility of X5 and X7 is also reflected by the shifts of the two vertices (corresponding to the positions of equilibrium phases 2 and 3) of the 
triangular L3 region from $\left(x_{s_{3}}^{(3)}, x_{s_{2}}^{(3))}=(0.219,0.609)\right.$ in Fig. $2 \mathrm{a}$ to $\left(x_{s_{3}}^{(3)}, x_{s_{2}}^{(3))}=(0.105,0.582) \quad\right.$ in Fig. $6 \mathrm{~b}$ and from $\left(x_{s_{3}}^{(3)}, x_{s_{2}}^{(3))}=(0.372,0.00233)\right.$ to $\left(x_{s_{3}}^{(2)}, x_{s_{2}}^{(2))}=(0.209,0.000181)\right.$, respectively. Therefore, the L3 region decreases in area and shifts to a relatively higher water concentration. On the contrary, the change in phase structure for $\mathrm{X} 5 / \mathrm{X} 7$ can be attributed to the decreasing interaction between $\mathrm{OH} / \mathrm{COOH}$, resulting in decreased miscibility between $\mathrm{X} 5$ and $\mathrm{X} 7$ when replacing UNIFAC by UNIFAC-Peng with the two-liquid region enlarged from $(0.5367,0.9334)$ to $(0.4528,0.9465)$ in terms of the mole fraction of $\mathrm{X} 7$. The combined effect of the increasing interactions between $\mathrm{OH} / \mathrm{H}_{2} \mathrm{O}$ and $\mathrm{COOH} / \mathrm{H}_{2} \mathrm{O}$ and the decreasing interaction between $\mathrm{OH} / \mathrm{COOH}$ leads to an increased L2 (two-liquid) region that is bounded between the right edge of the triangular shaped L3 region and the off-diagonal axis where the mixture separates along the tie-lines into two mixed organic phases, one (1-hexacosanol dominating organic phase) of which includes higher concentrations of 1-hexacosanol and the other (pinic acid dominating organic phase) of which includes slightly higher pinic acid when replacing UNIFAC with UNIFAC-Peng.

\subsection{UNIFAC vs. UNIFAC-LL}

Unlike the UNIFAC interaction parameters, which are fitted to vapor-liquid equilibrium data, the UNIFAC-LL interaction parameters were determined using liquid-liquid equilibrium data. For example, the interaction parameter $\left(\mathrm{A}_{m n}\right)$ for $\mathrm{OH}-\mathrm{H}_{2} \mathrm{O}$ decreases from 353.3 (UNIFAC) to 28.73 (UNIFAC-LL), leading to an increase of value 0.6 in the interaction term $\Psi_{m n}$. Concurrently, the $\mathrm{H}_{2} \mathrm{O}-\mathrm{OH}$ parameter changes from -229.1 (UNIFAC) to -122.4 (UNIFAC-LL), leading to a decrease of value 1.0 in the interaction term $\Psi_{n m}$. The decrease in the $\Psi_{m n}\left(\mathrm{OH}-\mathrm{H}_{2} \mathrm{O}\right)$ is greater than the increase in $\Psi_{n n}\left(\mathrm{H}_{2} \mathrm{O}-\mathrm{OH}\right)$ in magnitude, so the overall effect is a decrease in the interaction between $\mathrm{OH} / \mathrm{H}_{2} \mathrm{O}$. Similarly, changes in the interaction parameters from UNIFAC to UNIFAC-LL cause an overall increase in the $\mathrm{COOH} / \mathrm{H}_{2} \mathrm{O}$ interaction, and a negligible decrease in the $\mathrm{OH} / \mathrm{COOH}$ interaction, as shown in Table 5. Different from UNIFAC vs. UNIFAC-Peng, in addition to the $\mathrm{OH}, \mathrm{COOH}, \mathrm{H}_{2} \mathrm{O}$ group-group interactions, there are also differences for UNIFAC vs. UNIFAC-LL in the $\mathrm{CH}_{2}, \mathrm{OH}, \mathrm{COOH}, \mathrm{H}_{2} \mathrm{O}$ pairwise interactions. In summary, the effect on $\mathrm{CH}_{2} / \mathrm{OH}$ and $\mathrm{CH}_{2} / \mathrm{H}_{2} \mathrm{O}$ of changing from UNIFAC to UNIFAC-LL is a decrease in the interaction, while the interaction between $\mathrm{CH}_{2} / \mathrm{COOH}$ increases. The changes between Figs. $6 \mathrm{~b}$ and $2 b$ in terms of phase structures predicted for the system water/1-hexacosanol(X5)/pinic acid(X7) using UNIFAC-LL vs. UNIFAC parameters can also be analyzed by comparing the phase diagrams of their corresponding binary systems. The competing effects of an increasing interaction between $\mathrm{OH} / \mathrm{H}_{2} \mathrm{O}$ (with a weight of value 1 being the number of $\mathrm{OH}$ groups in X5) and decreasing interactions between $\mathrm{CH}_{2} / \mathrm{OH}$ and $\mathrm{CH}_{2} / \mathrm{H}_{2} \mathrm{O}$ (both with a weight of value 25 being the number of $\mathrm{CH}_{2}$ groups in $\mathrm{X} 5$ ) results in a slightly decreased miscibility of X5 from 0.1016 to 0.0858 when replacing UNIFAC by UNIFAC-Peng. Similarly, the competing effects of increasing interactions between $\mathrm{COOH} / \mathrm{H}_{2} \mathrm{O}$ (with a weight of value 2 being the number of $\mathrm{COOH}$ groups in $\mathrm{X} 7$ ) and $\mathrm{CH}_{2} / \mathrm{COOH}$ (with a weight of value 4 being the product of the numbers of $\mathrm{COOH}$ groups and $\mathrm{CH}_{2}$ groups in $\mathrm{X7}$ ), and a decreasing interactions between $\mathrm{CH}_{2} / \mathrm{H}_{2} \mathrm{O}$ (with a weight of value 2 being the number of $\mathrm{CH}_{2}$ groups in $\mathrm{X7}$ ) results in a negligibly increased miscibility of X7 from 0.6345 to 0.6492 when replacing UNIFAC by UNIFAC-Peng. Also, the effect of the increasing interaction between $\mathrm{CH}_{2} / \mathrm{COOH}$ (with a weight of value 50 being the product of numbers of $\mathrm{CH}_{2}$ groups in $\mathrm{X} 5$ and $\mathrm{COOH}$ groups in $\mathrm{X7}$ ) overweights the combined effect of decreasing interactions between $\mathrm{CH}_{2} / \mathrm{OH}$ (with a weight of value 2 being the product of the numbers of $\mathrm{CH}_{2}$ groups in $\mathrm{X} 7$ and $\mathrm{OH}$ groups in $\mathrm{X} 5$ ) and $\mathrm{OH} / \mathrm{COOH}$ (with a weight of value 2 being the product of the numbers of $\mathrm{COOH}$ groups in $\mathrm{X} 7$ and $\mathrm{OH}$ groups in $\mathrm{X} 5$ ), resulting in a drastically increased miscibility between $\mathrm{X} 5$ and $\mathrm{X} 7$ from a partial miscibility to a full miscibility, leading to the formation of a new (and larger) single phase region that covers all the points with high organic mole fractions of X5 and $X 7$. At the points when the mole fraction of water is not small $(>0.1)$, the effect of the decreasing interaction between $\mathrm{CH}_{2} / \mathrm{H}_{2} \mathrm{O}$ (with a weight of value 27 being the sum of the number of $\mathrm{CH}_{2}$ groups in $\mathrm{X} 5$ and $\mathrm{X} 7$ ) balances the effect of the increasing interaction between $\mathrm{CH}_{2} / \mathrm{COOH}$, results in a partial miscibility between $\mathrm{X} 5$ and $\mathrm{X} 7$ in the presence of non-negligible water, leading to a shift of the vertex $\left(x_{s_{3}}^{(3)}, x_{s_{2}}^{(3))}\right.$, which corresponds to the equilibrium phase 3 , from $(0.219,0.609)$ in Fig. 2a to $(0.424,0.451)$ in Fig. 6a. With an increase in $\mathrm{COOH} / \mathrm{H}_{2} \mathrm{O}$ interaction and decrease in the $\mathrm{OH} / \mathrm{H}_{2} \mathrm{O}$ interaction, three-phase separation occurs at the region of lower mole fractions of 1-hexacosanol and higher mole fractions of pinic acid. In addition, the L2 region on the left expands in area. With the similar range of 1-hexacosanol mole fraction, the L2 region in Fig. 6a extends to include a mixture with a maximum pinic acid mole fraction of 0.424 , instead of the original pinic acid mole fraction of 0.219 . Within this $\mathrm{L} 2$ region, the solution separates into a mixed organics (with some amount of water) phase and a nearly pure water aqueous phase. The increase in $\mathrm{CH}_{2} / \mathrm{COOH}$ interaction between the $25 \mathrm{CH}_{2}$ groups of 1-hexacosanol and the $2 \mathrm{COOH}$ groups of pinic acid is expected to be greater than the decrease in $\mathrm{CH}_{2} / \mathrm{OH}$ interaction between the $2 \mathrm{CH}_{2}$ groups of pinic acid and $1 \mathrm{OH}$ group of 1-hexacosanol, causing an increased interaction between 1hexacosanol and pinic acid. Hence, the L2 region is extended to a higher mole fraction of pinic acid.

Since most of the parameters between UNIFAC and UNIFAC-LL differ, and the effect is often competitive, the 
phase diagram predicted using UNIFAC-LL significantly varies from that predicted by UNIFAC.

\section{Conclusions}

Presented here is the extension of the UHAERO aerosol thermodynamic model to organic/water systems. Special attention is paid to calculating the liquid phase equilibria occurring in relatively complex mixtures of organics and water. Through a merging of the inorganic and organic modules of UHAERO, we calculate inorganic/organic/water phase diagrams that show the effect of mixtures of organics on inorganic deliquescence behavior. Since the fundamental chemical information required to construct phase diagrams for such systems is the component activities, we show the sensitivity of one of the calculated phase diagrams to the choice of activity coefficient model; differences in the phase diagrams are related to differences in interaction parameter values in the different versions of the UNIFAC model.

Current atmospheric models for secondary organic aerosol generally assume that two liquid phases exist, one of which is relatively polar (containing mostly water and electrolytes) and the other mostly organic (containing primarily nonelectrolytes); see, for example, Pun et al. (2002) and Griffin et al. $(2003,2005)$. The results in the current work allow one to assess the extent to which this assumption is valid for the particular mixture of compounds simulated in an atmospheric model.

The method presented here affords a rigorous computation of inorganic/organic/water phase equilibria. While such liquid/solid phase equilibrium computations may not be necessary in a 3-D atmospheric chemical transport model, the results of the UHAERO model are a benchmark to which more approximate thermodynamic models may be compared.

Acknowledgements. This work was supported by U.S. Environmental Protection Agency grant X-83234201. The third author acknowledges the support by the NSF under Grant No. DMS0511611 .

Edited by: A. Nenes

\section{References}

Amundson, N. R., Caboussat, A., He, J. W., Seinfeld, J. H., and Yoo, K. Y.: An optimization problem related to the modeling of atmospheric inorganic aerosols, C. R. Acad. Sci. Paris, Ser. I, 340, 683-686, doi:10.1016/j.crma.2005.01.025, 2005a.

Amundson, N. R., Caboussat, A., He, J. W., and Seinfeld, J. H.: An optimization problem related to the modeling of atmospheric organic aerosols, C. R. Acad. Sci. Paris, Ser. I, 340, 765-768, doi:10.1016/j.crma.2005.04.018, 2005 b.
Amundson, N. R., Caboussat, A., He, J. W., Seinfeld, J. H., and Yoo, K. Y.: Primal-dual active-set algorithm for chemical equilibrium problems related to the modeling of atmospheric inorganic aerosols, J. Optimization Theory Appl., 128(3), 469-498, doi:10.1007/s10957-006-9030-y, 2006a.

Amundson, N. R., Caboussat, A., He, J. W., and Seinfeld, J. H.: Primal-dual interior-point method for an optimization problem related to the modeling of atmospheric organic aerosols, J. Optimization Theory Appl., 130(3), 375-407, doi:10.1007/s10957006-9110-z, $2006 \mathrm{~b}$.

Amundson, N. R., Caboussat, A., He, J. W., Martynenko, A. V., Savarin, V. B., Seinfeld, J. H., and Yoo, K. Y.: A new inorganic atmospheric aerosol phase equilibrium model (UHAERO), Atmos. Chem. Phys., 6(4), 975-992, 2006c.

Amundson, N. R., Caboussat, A., He, J. W., Martynenko, A. V., and Seinfeld, J. H.: A phase equilibrium model for atmospheric aerosols containing inorganic electrolytes and organic compounds (UHAERO), with applications to dicarboxylic acids, J. Geophys. Res., in press, 2007.

Ansari, A. S. and Pandis, S. N.: Water absorption by secondary organic aerosol and its effect on inorganic aerosol behavior, Environ. Sci. Technol., 34(1), 71-77, 2000.

Clegg, S. L. and Pitzer, K. S.: Thermodynamics of multicomponent, miscible, ionic solutions: generalized equations for symmetrical electrolytes, J. Phys. Chem., 96, 3513-3520, 1992.

Clegg, S. L. and Seinfeld, J. H.: Thermodynamic models of aqueous solutions containing electrolytes and dicarboxylic acids at $298.15 \mathrm{~K} 1$. the acids as nondissociating components, J. Phys. Chem., 110, 5692-5717, 2006a.

Clegg, S. L. and Seinfeld, J. H.: Thermodynamic models of aqueous solutions containing electrolytes and dicarboxylic acids at $298.15 \mathrm{~K} \mathrm{2}$. systems including dissociation equilibria, J. Phys. Chem., 110, 5718-5734, 2006 b.

Clegg, S. L., Brimblecombe, P., and Wexler, A.S.: A thermodynamic model of the system $\mathrm{H}^{+}-\mathrm{NH}_{4}^{+}-\mathrm{Na}^{+}-\mathrm{SO}_{4}^{2-}-\mathrm{NO}_{3}^{-}-\mathrm{Cl}^{-}$. $\mathrm{H}_{2} \mathrm{O}$ at 298.15 K, J. Phys. Chem., 102, 2155-2171, 1998a.

Clegg, S. L., Brimblecombe, P., and Wexler, A. S.: A thermodynamic model of the system $\mathrm{H}^{+}-\mathrm{NH}_{4}^{+}-\mathrm{SO}_{4}^{2-}-\mathrm{NO}_{3}^{-}-\mathrm{H}_{2} \mathrm{O}$ at tropospheric temperatures, J. Phys. Chem., 102, 2137-2154, 1998b.

Clegg, S. L., Pitzer, K. S., and Brimblecombe, P.: Thermodynamics of multicomponent, miscible, ionic solutions. mixtures including unsymmetrical electrolytes, J. Phys. Chem., 96(23), 9470-9479, 1992.

Clegg, S. L., Seinfeld, J. H., and Brimblecombe, P.: Thermodynamic modelling of aqueous aerosols containing electrolytes and dissolved organic compounds., J. Aerosol. Sci., 32, 713-738, 2001.

Clegg, S. L., Seinfeld, J. H., and Edney, E. O.: Thermodynamic modelling of aqueous aerosols containing electrolytes and dissolved organic compounds: ii. an extended ZdanovskiiStokes-Robinson approach, J. Aerosol Sci., 34, 667-690, 2003.

Fredenslund, A., Gmehling, J., and Rasmussen, P.: Vapor-Liquid Equilibrium Using UNIFAC, Elsevier, Amsterdam, 1977.

Gmehling, J.: Group contribution methods - ideal tools for the synthesis and design of separation processes, Pure Appl. Chem., 71(6), 939-949, 1999.

Griffin, R. J., Dabdub, D., and Seinfeld, J. H.: Secondary organic aerosol 1. Atmospheric chemical mechanism for production of molecular constituents, J. Geophys. Res., 107(D17), 
4332, doi:10.1029/2001JD000541, 2002.

Griffin, R. J., Nguyen, K., Dabdub, D., and Seinfeld, J. H.: A coupled hydrophobic-hydrophilic model for predicting secondary organic aerosol formation, J. Atmos. Chem., 44, 171-190, 2003.

Griffin, R. J., Dabdub, D., and Seinfeld, J. H.: Development and initial evaluation of a dynamic species-resolved model for gasphase chemistry and size-resolved gas/particle partitioning associated with secondary organic aerosol formation, J. Geophys. Res., 110, D05304, doi:10.1029/2004JD005219, 2005.

Hansen, H. K., Rasmussen, P., Fredenslund, A., Schiller, M., and Gmehling, J.: Vapor-liquid equilibria by UNIFAC group contribution. 5. revision and extension, Ind. Eng. Chem. Proc. Design Develop., 30(10), 2352-2355, 1991.

Magnussen, T., Rasmussen, P., and Fredenslund, A.: UNIFAC parameter table for prediction of liquid-liquid equilibria, Ind. Eng. Chem. Proc. Design Develop., 20, 331-339, 1981.

Metzger, S., Mihalopoulos, N., and Lelieveld, J.: Importance of mineral cations and organics in gas-aerosol partitioning of reactive nitrogen compounds: case study based on MINOS results, Atmos. Chem. Phys., 6, 2549-2567, 2006, http://www.atmos-chem-phys.net/6/2549/2006/.

Ming, Y. and Russell, L. M.: Thermodynamic equilibrium of organic-electrolyte mixtures in aerosol particles, AIChE J., 48(6), 1331-1348, 2002.

Pankow, J. E., Seinfeld, J. H., Asher, W. E., and Erdakos, G. B.: Modeling the formation of secondary organic aerosol (soa). 1. the application of theoretical principles to measurements obtained in the $\alpha$-pinene-, $\beta$-pinene-, sabinene-, $\Delta 3$-carene, and cyclohexene-ozone systems, Environ. Sci. Technol., 35, 11641172, 2001.

Peng, C., Chan, M. N., and Chan, C.: The hygroscopic properties of dicarboxylic and multifunctional acids: measurements and UNIFAC predictions, Environ. Sci. Technol., 35(22), 44954501, 2001.
Pun, B. K., Griffin, R. J., Seigneur, C., and Seinfeld, J. H.: Secondary organic aerosol 2 . Thermodynamic model for gas/particle partitioning of molecular constituents, J. Geophys. Res., 107, 4333, doi:10.1029/2001JD000542, 2002.

Raatikainen, T. and Laaksonen, A.: Application of several activity coefficient models to water-organic-electrolyte aerosols of atmospheric interest, Atmos. Chem. Phys., 5, 2475-2495, 2005, http://www.atmos-chem-phys.net/5/2475/2005/.

Sandler, S. I.: Chemical and Engineering Thermodynamics, Wiley, 1999.

Saxena, P. and Hildemann, L. M.: Water absorption by organics: survey of laboratory evidence and evaluation of UNIFAC for estimating water activity, Environ. Sci. Technol., 31(11), 33183324, 1997.

Seinfeld, J. H., Erdakos, G. B., Asher, W. E., and Pankow, J. E.: modeling the formation of secondary organic aerosol (soa). 2. the predicted effects of relative humidity on aerosol formation in the $\alpha$-pinene-, $\beta$-pinene-, sabinene-, $\Delta 3$-carene, and cyclohexeneozone systems, Environ. Sci. Technol., 35, 1806-1817, 2001.

Tang, I. N.: Phase transformation and growth of aerosol particles composed of mixed salts, J. Aerosol Sci., 7, 361-371, 1976.

Topping, D. O., McFiggans, G. B., and Coe, H.: A curved multicomponent aerosol hygroscopicity model framework: Part 2 : Including organic compounds, Atmos. Chem. Phys., 5, 12231242, 2005, http://www.atmos-chem-phys.net/5/1223/2005/.

Wittig, R., Lohmann, J., and Gmehling, J.: Vapor-liquid equilibria by UNIFAC group contribution. 6. revision and extension, Ind. Eng. Chem. Proc. Design Develop., 42(1), 183-188, 2003. 